\title{
Tick extracellular vesicles enable arthropod feeding and promote distinct outcomes of bacterial infection
}

\author{
Adela S. Oliva Chávez (1) 1,18, Xiaowei Wang', Liron Marnin', Nathan K. Archer (1) 2, Holly L. Hammond', \\ Erin E. McClure Carroll,19, Dana K. Shaw (1) 1,20, Brenden G. Tully ${ }^{3}$, Amanda D. Buskirk ${ }^{4,21}$, Shelby L. Ford ${ }^{5}$, \\ L. Rainer Butler ${ }^{1}$, Preeti Shahi ${ }^{1}$, Kateryna Morozova ${ }^{6}$, Cristina C. Clement $^{6,22}$, Lauren Lawres ${ }^{7}$, \\ Anya J. O' Neal (D) 1, Choukri Ben Mamoun (1) 7, Kathleen L. Mason ${ }^{8}$, Brandi E. Hobbs (D) 1, Glen A. Scoles ${ }^{8,23}$, \\ Eileen M. Barry (1) ${ }^{4}$, Daniel E. Sonenshine ${ }^{9,10}$, Utpal Pal ${ }^{11}$, Jesus G. Valenzuela9 ${ }^{9}$ Marcelo B. Sztein ${ }^{4,12,13}$, \\ Marcela F. Pasetti ${ }^{4,12}$, Michael L. Levin ${ }^{5}$, Michail Kotsyfakis (1) ${ }^{14}$, Steven M. Jay (1) ${ }^{15}$, Jason F. Huntley ${ }^{3}$, \\ Lloyd S. Miller ${ }^{2,16}$, Laura Santambrogio (1) ${ }^{17,22} \&$ Joao H. F. Pedra (iD) ${ }^{1 凶}$
}

Extracellular vesicles are thought to facilitate pathogen transmission from arthropods to humans and other animals. Here, we reveal that pathogen spreading from arthropods to the mammalian host is multifaceted. Extracellular vesicles from Ixodes scapularis enable tick feeding and promote infection of the mildly virulent rickettsial agent Anaplasma phagocytophilum through the SNARE proteins Vamp33 and Synaptobrevin 2 and dendritic epidermal $T$ cells. However, extracellular vesicles from the tick Dermacentor andersoni mitigate microbial spreading caused by the lethal pathogen Francisella tularensis. Collectively, we establish that tick extracellular vesicles foster distinct outcomes of bacterial infection and assist in vector feeding by acting on skin immunity. Thus, the biology of arthropods should be taken into consideration when developing strategies to control vector-borne diseases.

\footnotetext{
${ }^{1}$ Department of Microbiology and Immunology, University of Maryland School of Medicine, Baltimore, MD, USA. ${ }^{2}$ Department of Dermatology, Johns Hopkins University School of Medicine, Baltimore, MD, USA. ${ }^{3}$ Department of Medical Microbiology and Immunology, University of Toledo College of Medicine and Life Sciences, Toledo, OH, USA. ${ }^{4}$ Center for Vaccine Development and Global Health, University of Maryland School of Medicine, Baltimore, MD, USA. ${ }^{5}$ Centers for Disease Control and Prevention, Atlanta, GA, USA. ${ }^{6}$ Department of Pathology, Albert Einstein College of Medicine, Bronx, NY, USA. ${ }^{7}$ Section of Infectious Diseases, Department of Internal Medicine, Yale University School of Medicine, New Haven, CT, USA. ${ }^{8}$ USDA, ARS, Animal Disease Research Unit, Washington State University, Pullman, WA, USA. ${ }^{9}$ Vector Molecular Biology Section, Laboratory of Malaria and Vector Research, National Institute of Allergy and Infectious Diseases, National Institutes of Health, Rockville, MD, USA. ${ }^{10}$ Department of Biological Sciences, Old Dominion University, Norfolk, VA, USA. ${ }^{11}$ Department of Veterinary Medicine, University of Maryland, College Park, MD, USA. ${ }^{12}$ Department of Pediatrics, University of Maryland School of Medicine, Baltimore, MD, USA. ${ }^{13}$ Department of Medicine, University of Maryland School of Medicine, Baltimore, MD, USA. ${ }^{14}$ Institute of Parasitology, Biology Center of the Czech Academy of Sciences, Ceske Budejovice, Czech Republic. ${ }^{15}$ Fischell Department of Bioengineering, University of Maryland, College Park, MD, USA. ${ }^{16}$ Immunology, Janssen Research and Development, Spring House, PA, USA. ${ }^{17}$ Department of Microbiology and Immunology, Albert Einstein College of Medicine, Bronx, NY, USA. ${ }^{18}$ Present address: Department of Entomology, Texas A\&M University, College Station, TX, USA. ${ }^{19}$ Present address: Excerpta Medica, Doylestown, PA, USA. ${ }^{20}$ Present address: Department of Veterinary Microbiology and Pathology, Washington State University, Pullman, WA, USA. ${ }^{21}$ Present address: Center for Drug Evaluation and Research, Office of Pharmaceutical Quality, Office of Process and Facilities, Division of Microbiology Assessment, Microbiology Assessment Branch III, U.S. Food and Drug Administration, Silver Spring, MD, USA. ${ }^{22}$ Present address: Department of Radiation Oncology and Physiology and Biophysics, Englander Institute for Precision Medicine, Weill Cornell Medicine, New York,

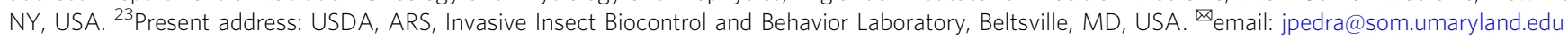


A rthropod vectors transmit a diverse portfolio of bacterial, viral, and parasitic agents to mammals ${ }^{1}$. This evolutionary feat is partly due to the secretion of salivary molecules that disrupt host homeostasis and alter inflammation upon blood-feeding ${ }^{2-4}$. Salivary molecules from arthropod vectors redirect host immunity, enable microbial spreading and influence disease outcomes in humans and other animals ${ }^{2-4}$. For instance, saliva from the sandfly Lutzomyia longipalpis enhances transmission of the parasite Leishmania major ${ }^{5}$. Salivary effectors present in mosquitoes potentiate arbovirus transmission and augment disease severity in the mammalian host ${ }^{6,7}$. Tick molecules inhibit inflammation and increase transmission of viruses and bacteria to a variety of animals ${ }^{8-11}$.

Although saliva-assisted transmission appears to be universal among arthropods that feed on blood $2,3,12$, the mechanisms that affect interspecific responses reflect unique interactions occurring between vectors and their hosts. As an example, the inflammatory response caused by the bite of the mosquito Aedes aegypti, which is classically assumed to defend the mammalian host against arboviral infection, results in higher Semliki forest and Bunyamwera viral load ${ }^{13}$. Depletion of neutrophils and inhibition of inflammasome activity dampens the mosquito's ability to enable viral transmission ${ }^{13}$. Infiltration of neutrophils at the sand fly bite site, which is typically judged to be microbicidal, is important for L. major infection and establishment of illness ${ }^{14}$. Altogether, these studies suggest that the relationship between salivary components, host immunity and microbial transmission are complex and ill-defined.

Extracellular vesicles (EVs) are a heterogenous population of nanovesicles that mediate interspecies communication ${ }^{15-17}$. Exosomes, a subset of EVs that range from approximately 50 to $150 \mathrm{~nm}$ in size, are enriched for certain proteins, lipids, nucleic acids, and glycoconjugates ${ }^{15-17}$. Recently, exosomes were shown to facilitate arbovirus transmission to mammals ${ }^{18-21}$ and two studies examined the molecular cargo of extracellular vesicles originated from the evolutionarily distant Asian longhorned tick Haemaphysalis longicornis ${ }^{22,23}$. The functional plasticity and immunomodulatory potential of arthropod exosomes during vector transmission remain mostly unknown. To address this question, we used ticks as arthropod models due to their longfeeding behavior and medical importance ${ }^{24}$. Herein, we adapted a protocol to culture tick salivary glands ${ }^{25-27}$ and developed a salivary organoid system that mimics EV release. We also characterized the proteomic composition of these EVs in adult Ixodes scapularis and show that EVs derived from cultured cells and salivary glands have a different cargo and post-translational profile.

In this work, we expand the current model for arthropod vector feeding on mammals by showing that tick EVs affect dendritic epidermal $\mathrm{T}$ cells (DETCs) ${ }^{28-30}$. DETCs are a specialized subset of $\gamma \delta \mathrm{T}$ cells involved in wound healing and present exclusively in the murine skin epidermis ${ }^{28-35}$. Furthermore, we indicate that EVs enable tick feeding and foster distinct outcomes of bacterial infection in mammals. EVs from the deer tick $I$. scapularis facilitate infection of the mildly virulent rickettsial agent Anaplasma phagocytophilum in the mammalian host. Conversely, EVs from the tick Dermacentor andersoni reduce spreading of the deadly pathogen Francisella tularensis in a murine model.

\section{Results}

Ticks secrete salivary effectors within diverse EVs. We developed a methodology for recovering tick EVs from cells and organs in an EV-depleted medium (Supplementary Fig. 1a, b). EVs from the blacklegged tick I. scapularis were heterogenous, as shown by transmission electron microscopy (Fig. 1a). In silico reconstruction of the $\mathrm{EV}$ pathway based on the I. scapularis genome $^{36}$ identified genes associated with exosome biogenesis and secretion (Supplementary Data 1). These molecules included the tetraspanin CD63 and two proteins associated with the endosomal sorting complex required for transport (ESCRT) machinery: (i) $\alpha-1,3 / 1,6$-mannosyltransferase interacting protein $\mathrm{X}$ (ALIX) and the (ii) tumor susceptibility gene 101 protein (TSG101) ${ }^{15-17}$. Mammalian polyclonal antibodies cross-reacted with markers present in EVs originated from three tick cell lines: (i) Amblyomma americanum (i.e., vector of ehrlichiosis ${ }^{37}$ - AAE2 cells); (ii) I. scapularis (i.e., vector of Lyme disease and Anaplasmosis $^{24}$ - ISE6 cells); and (iii) D. andersoni (i.e., vector of tularemia $^{38}$ - DAE100 cells) (Fig. $1 \mathrm{~b}$ and Supplementary Fig. 1c-e). These EVs presented an average mean size of $173 \pm 7$, $137 \pm 6$, and $183 \pm 3 \mathrm{~nm}$, respectively (Supplementary Fig. 1f-h and Supplementary Movies 1-3).

To study the effect of $I$. scapularis EVs, we silenced the expression of two tick soluble $\mathrm{N}$-ethylmaleimide-sensitive factor attachment receptor (SNARE) genes (e.g., synaptobrevin 2 and vamp33) through RNA interference (RNAi). Tick studies rely on delivering small interfering RNA (siRNA) to modulate gene expression because complete genetic ablation within ticks is not currently feasible ${ }^{39}$. No differences in cell viability were observed between the scrambled (sc) control and silenced (si) treatments (Supplementary Fig. 2a). Nanoparticle tracking analysis (NTA) revealed decreased secretion of tick vesicles in the classical exosomal range (i.e., $50-150 \mathrm{~nm}$ ) for both synaptobrevin 2 and vamp33 siRNA-treated cells (Fig. 1c, Supplementary Fig. 2b-d, and Supplementary Movies 4-7).

EVs derived from adult $I$. scapularis salivary glands had an average mean size of $198 \pm 4 \mathrm{~nm}$ (Fig. 1d and Supplementary Movie 8). We then obtained EVs from dissected I. scapularis salivary glands cultured ex vivo in a vesicle-free medium to analyze their protein content. High-throughput proteomics analysis of their cargo demonstrated a heterogeneous population with proteins typically featured for microvesicles, exosomes, and exomeres $^{40}$ (Supplementary Fig. 2e, f, Supplementary Data 2-5, and data available via ProteomeXchange, identifier PXD018779). Tick proteins that have an impact on the immune response (e.g., sialostatins $)^{9}$ and molecules associated with oxidative stress, metabolism, and cell biology processes were overrepresented (Supplementary Figs. 3 and 4 and Supplementary Data 2). The presence of the exosomal markers CD63, ALIX, and TSG101 was detected in tick salivary EVs by immunoblots (Fig. 1e-g), as shown previously ${ }^{41}$. Moreover, a subset of proteins detected in our proteomics analysis was validated through western blots (Fig. 1h). Some proteins were present in all EVs surveyed (e.g., DHX16 and PLS3), while others were only detected in EVs originated from tick cells (e.g., CTNNB1) when compared to salivary glands (e.g., CCT7 and GFPT1). A similar pattern emerged for glycosylation in tick EVs (Fig. 1i), but this observation was less pronounced for phosphorylation (Fig. 1j) and carbonylation (Fig. 1k), a common product of protein oxidation ${ }^{42}$.

It was not possible to corroborate all our findings with EVs from tick saliva due to the limited material. Due to this technical limitation, we adopted a hybrid isolation model where we substantiated our results with EVs from tick saliva in I. ricinus, the main vector of Lyme disease in Europe ${ }^{43}$. This methodology was also recently used in EVs extracted from $I$. scapularis and Amblyomma maculatum to determine their effect on a human keratinocyte cell line ${ }^{41}$. Using this approach, we identified the tick protein Sialostatin L2 (SL2) 9 and the tetraspanin CD63 in EVs derived from adult saliva (Fig. 11). Altogether, our data suggested that ticks secrete a diverse group of EVs containing molecules capable of modulating mammalian host physiology. 

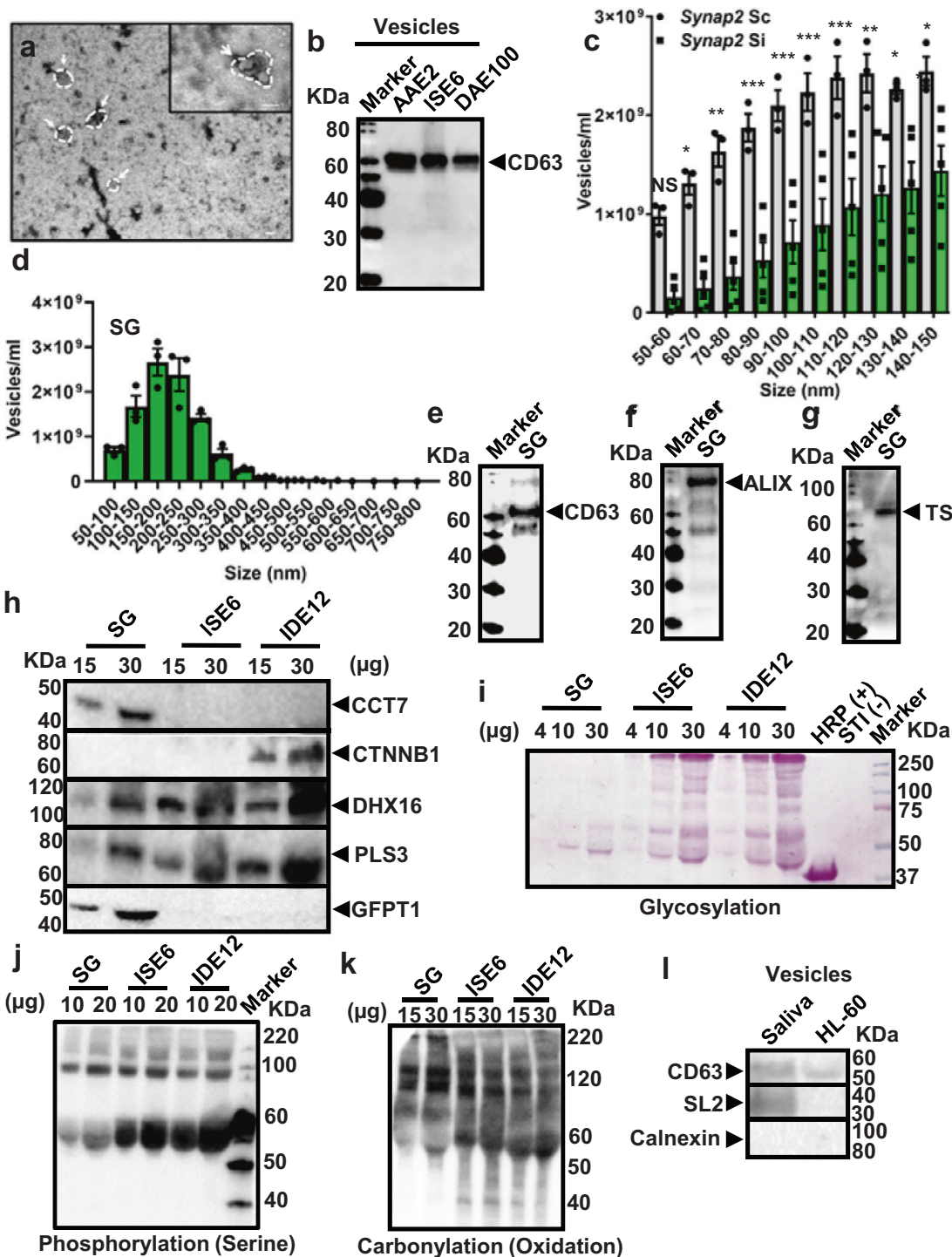

Fig. 1 Ticks secrete EVs with a distinct cargo profile. a Transmission electron microscopy of EVs released by I. scapularis (ISE6) cells. Scale bar: 100 nm, large panel $=11,000 x$; small panel $=30,000$ x. The image is representative of two independent experiments. b SDS-PAGE immunoblot showing CD63+ EVs purified from AAE2, ISE6, and DAE100 tick cells (70 $\mu$ g of protein). Images are a representation of three independent experiments. $\mathbf{c}$ l. scapularis ISE6 cells transfected with synaptobrevin 2 small interfering (Synaptobrevin 2 si) (green) or scrambled control RNA (Synaptobrevin 2 sc) (gray) to reduce the EV release. Concentration and size distribution of EVs were measured by nanoparticle tracking analysis (NTA). Mean \pm standard error of the mean (SEM) of technical replicates plotted from one of two independent experiments are shown. Similar results were obtained in both independent studies. Two-way ANOVA using size and treatment as variables followed by Sidak's multiple comparison statistical test of the same size vesicles between treatments. ${ }^{*} p<$ $0.05 ;{ }^{* \star} p<0.005$; ${ }^{\star \star *} ; p<0.001$; NS not significant. d EVs originated from I. scapularis salivary gland (SG) cultures. Mean \pm SEM are plotted. Data is representative of three independent experiments. e-g SDS-PAGE immunoblots showing CD63+, ALIX+, and TSG101+ EVs purified from I. scapularis SGs (24 $\mu$ g of protein). h CCT7, CTNNB1, DHX16, PLS3, and GFPT1 expression in EVs purified from partially engorged I. scapularis SG and uninfected tick cells. $\mathbf{i}$ Glycosylation of proteins in EVs purified from partially engorged I. scapularis SG and tick cells. HRP (+) represents the horseradish peroxidase positive control and STI (-) indicates the soybean trypsin inhibitor negative control for the assay. $\mathbf{j}, \mathbf{k}$ Phosphorylation and carbonylation of proteins in EVs purified from partially engorged I. scapularis SG and tick cells. I EVs purified from I. ricinus saliva and immunoblotted against CD63, Sialostatin L2 (SL2), and calnexin ( $15 \mu \mathrm{g}$ of protein). EVs from $\mathrm{HL}^{-} 60$ were used as control cells, whereas calnexin was used as a technical negative control. Blots are representative of two independent experiments. Source data are provided as a Source Data file.

Tick EVs interact with mammalian immune cells. We then postulated that molecules present in EVs bind to immune cells. Proteomics of I. scapularis EVs derived from salivary glands revealed an overrepresentation of proteins connected to cell biology, oxidative stress, and metabolism (Fig. 2a, b, Supplementary Figs. 3 and 4, and Supplementary Data 2 and 5). Integrins direct $\mathrm{EV}$ tropism to specific organs through molecular interactions in the extracellular matrix ${ }^{44}$. To test this concept, we incorporated a fluorescent dye with long aliphatic tails $(\mathrm{PKH} 26)^{45}$ into lipid regions of membranes from tick EVs. We also labeled the plasma membrane of murine bone marrow-derived macrophages (BMDMs) pre-treated with cytochalasin $\mathrm{D}$, an inhibitor of actin polymerization, to block phagocytosis. Laser scanning confocal microscopy coupled to live-cell imaging showed PKH26labeled EVs bound to murine BMDMs (Fig. $2 \mathrm{c}$ and Supplementary Movie 9) and time-lapse microscopy displayed saturation at $\sim 160$ min (Fig. 2d). Next, we labeled I. scapularis EVs with the lipophilic $3,3^{\prime}$-dioctadecyloxacarbocyanine (DiO) dye and murine 

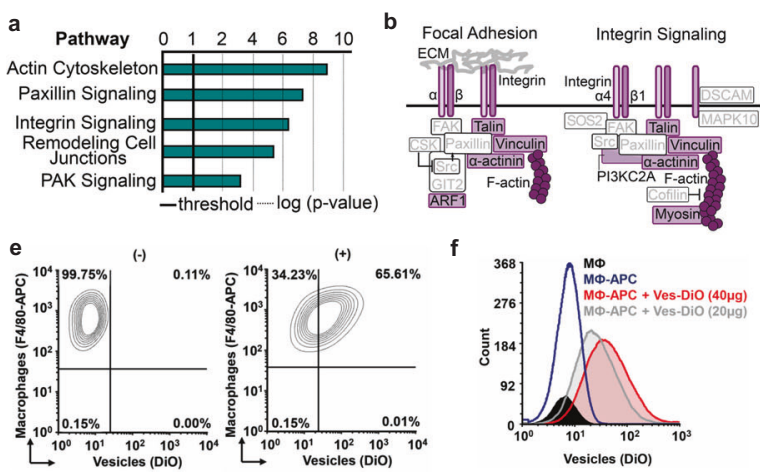
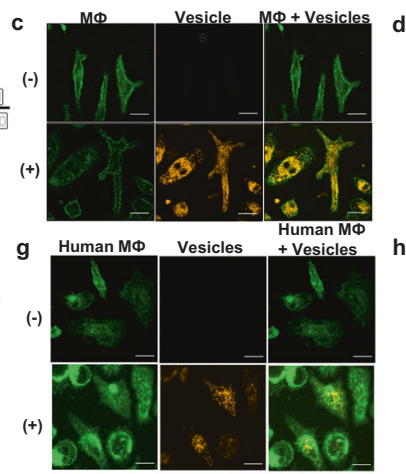
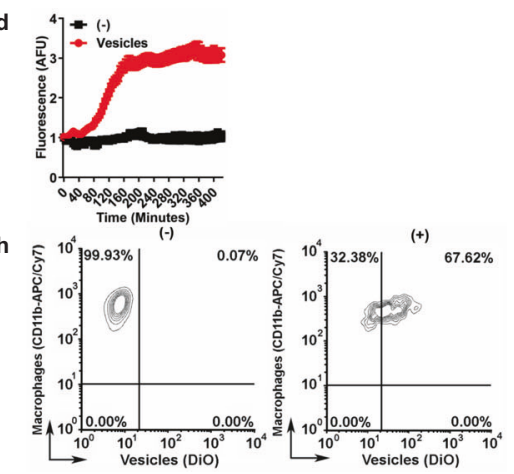

Fig. 2 Tick EVs bind to mammalian immune cells. a Overrepresentation of proteins involved in cell adhesion signaling networks in I. scapularis salivary gland EVs. The biological relationship between proteins was determined using the right-tailed Fisher's exact test with Benjamini-Hochberg multiple-testing correction. $p<0.05 ;-\log$ ( $p$ value) $>1.5$. b Graphic representation of focal adhesion and integrin signaling proteins (purple) found in I. scapularis salivary gland EVs. Confocal images of $\mathbf{c}$ murine bone marrow-derived macrophages (BMDMs) (bar $=20 \mu \mathrm{m})$ and $\mathbf{g}$ macrophages derived from human peripheral blood mononuclear cells (green) bound to I. scapularis EVs labeled with PKH26 (orange) (bar $=20 \mu \mathrm{m}$ ), respectively. Cells were pre-treated with cytochalasin D $(5 \mu \mathrm{M})$. ( -$)$ No EVs; (+) EVs. Images are representative of two independent experiments. d Arbitrary fluorescent units (AFU) of murine BMDMs bound to PKH26-labeled tick EVs (red). BMDMs incubated in the absence of EVs (black). Each time point represents the mean fluorescence from seven different cells minus background and normalized to time 0 . Graphs show one of two independent experiments. Flow cytometry with e murine BMDMs (F4/80+-APC) and $\mathbf{h}$ human macrophages (CD11b+-APC/Cy7) bound to DiO-labeled tick EVs (40 $\mu$ g), respectively. No EVs ( $)$; EVs (+). Figures are representative of three biological replicates. $\mathbf{f}$ Flow cytometry analysis of unlabeled BMDMs (black), F4/80-APC-labeled BMDMs (blue), F4/ 80-APC-labeled BMDMs bound to $40 \mu \mathrm{g}$ DiO-labeled tick EVs (red), and F4/80-APC-labeled BMDMs bound to $20 \mu \mathrm{g}$ of DiO-labeled and $20 \mu \mathrm{g}$ unlabeled tick EVs (gray). The histogram shows one of three biological replicates. PKH26 is a red fluorescent dye with long aliphatic tails ${ }^{45}$. In $\mathbf{c}, \mathbf{g}$, PKH26 was artificially transformed to an orange color to be visualized by color-blind readers. Source data are provided as a Source Data file.

BMDMs with the marker F4/80 conjugated to allophycocyanin (APC). F4/80+ murine macrophages bound to tick EVs in a dosedependent manner (Fig. 2e, f). Similarly, tick EVs bound to $\mathrm{CD} 11 \mathrm{~b}^{+}$human macrophages originated from peripheral blood mononuclear cells (PBMCs) (Fig. 2g, h). Collectively, our results indicated that arthropod EVs interact with immune cells.

Tick EVs redirect skin immunity. To assess whether tick EVs regulate an immune environment in vivo, we evaluated skin cell populations during I. scapularis hematophagy. Under normal tick-feeding, we observed increased inflammation in the murine skin, as inferred by an elevated presence of granulocytic and phagocytic cells and greater epidermal thickness (Supplementary Fig. 5). These findings were consistent with tick bites eliciting a visible innate immune response in the skin of humans ${ }^{46}$. Next, we performed RNAi silencing of vamp33 and synaptobrevin 2 in $I$. scapularis in vivo. For the sake of simplicity, we denominated arthropods that had vamp33 or synaptobrevin 2 gene expression reduced (vamp33 or synap2 si) as EV-deficient ticks. No difference in tick attachment was observed in the silenced versus the control treatment (Fig. 3a and Supplementary Fig. 6a, b). However, diminished feeding was measured for EV-deficient ticks (Fig. 3b and Supplementary Fig. 6c). Impaired tick feeding was linked to a change in the cytokine and chemokine milieu in the mouse skin. Notably, the skin immune environment was skewed towards an adaptive T helper 2 (Th2) wound healing response in mice fed on by EV-deficient ticks (Fig. 3c-e and Supplementary Fig. 7). Surprisingly, there was a $54 \%$ increase in the number of gamma delta $(\gamma \delta)$ T cells when EV-deficient ticks were placed on mice and compared to the control treatment (Fig. 3f and Supplementary Fig. 8). Increased numbers of $\gamma \delta \mathrm{T}$ cells at the skin site correlated to favored chemotactic conditions for immune cell recruitment during a tick bite ${ }^{47}$ (Fig. $3 g-j$ and Supplementary Fig. 7).

Depletion of DETCs rescues EV-dependent tick feeding at the skin site. $\gamma \delta \mathrm{T}$ cells were the only immune cells that showed an increased at the skin site after impairment of tick EVs (Fig. $3 \mathrm{f}$ and
Supplementary Fig. 8). Thus, we determined the effect of skin $\gamma \delta$ $\mathrm{T}$ cells on tick feeding. We first reduced the number of $\gamma \delta$ T cells in the murine skin through antibody depletion (Fig. 4a). We placed ticks injected with vamp33 siRNA on mice and measured their weight at day 3 post-attachment. We detected a $24 \%$ reduction in the weight of $\mathrm{EV}$-deficient ticks for the isotype control treatment (Fig. 4b, weight, two left-most rectangular bars [Isotype $\mathrm{Ab}$ ]). This decrease in weight was not observed when EV-deficient ticks (vamp33 si treatment) were placed on antibody-depleted $\gamma \delta$ T cell mice (Fig. 4b, weight, two right-most rectangular bars [Anti- $\gamma \delta \mathrm{Ab}])$. Similar results were obtained in animals genetically ablated for $\gamma \delta \mathrm{T}$ cells (Fig. 4c, weight, comparison in the two left-wildtype [WT] and right-most rectangular bars $\left[t c r \delta^{-/-}\right]$mice). Importantly, $\alpha \beta \mathrm{T}$ cells did not play any role in arthropod feeding. The weight of EV-deficient ticks (vamp33 si treatment) placed on animals genetically ablated for $\alpha \beta \mathrm{T}$ cells was reduced when compared to the control treatment (Fig. 4c, weight, comparison in the middle $\left[\operatorname{tcr} \beta^{-/-}\right]$). Taken together, our findings suggested that EVs regulate skin immunity through $\gamma \delta$ $T$ cells, providing an advantageous environment for tick feeding.

We then determined whether the effect of tick EVs was on resident or infiltrating $\gamma \delta \mathrm{T}$ cells. We placed ticks injected with vamp33 siRNA on mice with or without administering the molecule FTY720. FTY720 inhibits lymphocyte egress from lymph nodes ${ }^{48}$ (Fig. 4d). We did not observe any differences in the number of $\gamma \delta \mathrm{T}$ cells or the weight of EV-deficient ticks placed on FTY720-treated mice when compared to the control treatment (Fig. 4e). These findings indicated that tick EVs affect the resident, but not the infiltrating $\gamma \delta$ T cells during feeding.

Tick saliva may be injected in the epidermis, dermis, or the epidermis/dermis border depending on the tick mouthpart apparatus ${ }^{4,49}$. The $\gamma \delta \mathrm{T}$ cell population in the mouse skin is constituted of two distinct subpopulations, including dermal $\gamma \delta$ $\mathrm{T}$ cells (also known as $\gamma \delta$ T17 cells) that express the $\mathrm{T}$ cell receptor $\mathrm{V} \gamma 4$ or $\mathrm{V} \gamma 6^{30,50}$, and DETCs that express the $\mathrm{T}$ cell receptor $\mathrm{V} \gamma 5 \mathrm{~V} \delta 1$ in the epidermis ${ }^{28}$, according to the Heilig and Tonegawa nomenclature ${ }^{51}$. Thus far the effect of the tick bite has been predominantly reported to the dermis ${ }^{4,49}$. Therefore, we first 


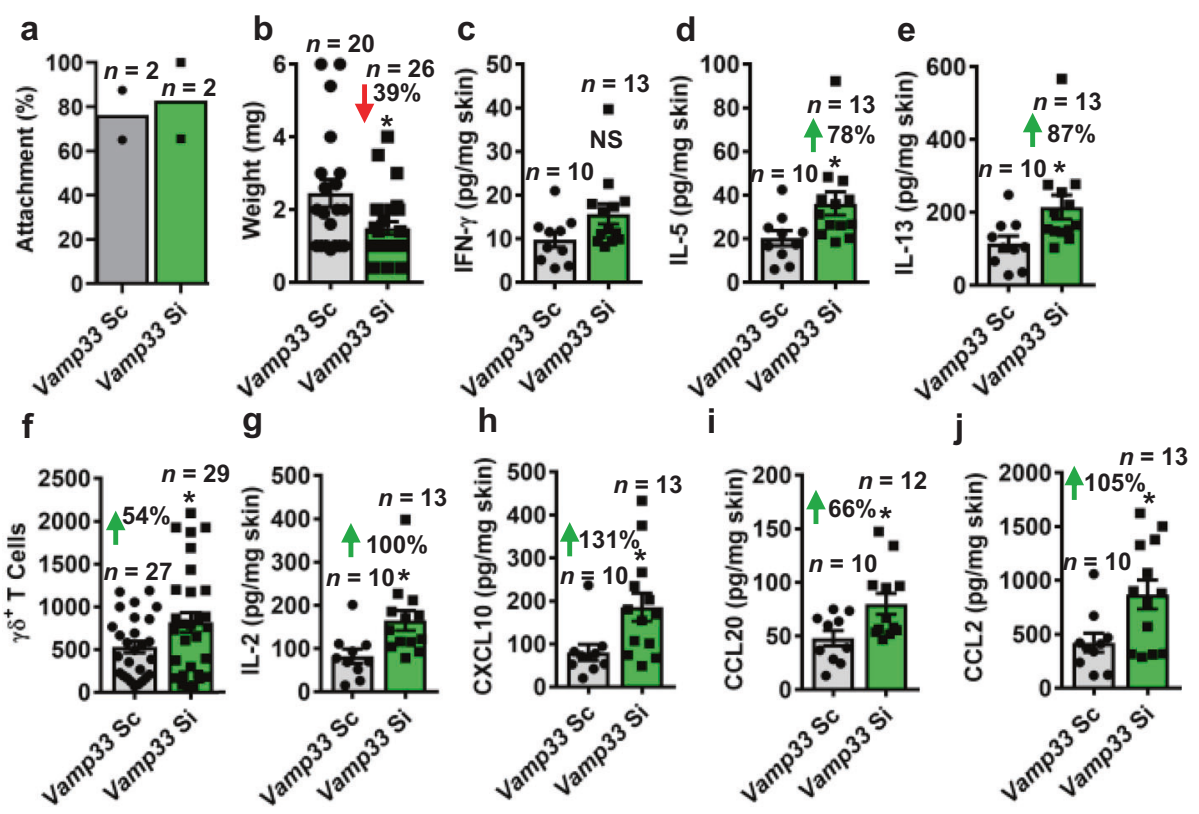

Fig. 3 Tick EVs affect the skin resident immune environment. a Attachment and $\mathbf{b}$ weight of $I$. scapularis ticks microinjected with vamp33 small interfering (Vamp33 si) (green) $(n=26)$ or scrambled (Vamp33 sc) (gray) $(n=20)$ RNA on C57BL/6 mice ( $n=2$ each treatment) after 3 days of feeding. Mean \pm standard error of the mean (SEM) are plotted. Data represent two independent experiments. Statistical differences were evaluated by two-tailed $t$ test. ${ }^{\star} p<$ 0.05. Effect of vamp33 si l. scapularis ticks on $\mathbf{c}$ interferon (IFN)- $\gamma$, d interleukin (IL)-5, and $\mathbf{e}$ IL-13 in the murine skin after 3 days of feeding. Increased $\mathbf{f} \gamma \delta$ T cells, $\mathbf{g}$ IL-2 and $\mathbf{h}-\mathbf{j}$ chemokine release at the bite site after Vamp33 si I. scapularis fed for 3 days on C57BL/6 mice. Mean \pm SEM are plotted. Cytokine and chemokine data represent a single experiment with multiple biological replicates, whereas data with skin immune cells represent three independent experiments combined. Statistical differences in $\mathbf{d}-\mathbf{j}$ were evaluated by two-tailed $t$ test. ${ }^{*} p<0.05$. NS not significant. $n$ number of samples. Source data are provided as a Source Data file.

investigated dermal $\gamma \delta$ T cells in the context of tick EV secretion. Dermal $\gamma \delta \mathrm{T}$ cells rely on the chemokine receptors CCR2 and CCR6 for cell recruitment to inflammatory sites and CCR2 for homeostatic trafficking ${ }^{47}$. We placed ticks injected with vamp33 siRNA on $c c r 2^{-/-}$and $c c r 6^{-/-}$mice. Surprisingly, genetic ablation of CCR2 or CCR6 did not affect EV-dependent tick feeding (Supplementary Fig. 9), suggesting that the dermal $\gamma \delta$ $\mathrm{T}$ cells were not involved in tick feeding mediated by EVs.

Subsequently, we examined the role of $\left(\mathrm{V} \gamma 5^{+} \mathrm{V} \delta 1^{+}\right)$DETCs during tick feeding ${ }^{28,29}$. We observed a greater thickening of the mouse epidermis during a tick bite (Supplementary Fig. 5b), which correlated with the epidermal function of DETCs ${ }^{28,29}$. Therefore, we placed ticks injected with vamp33 siRNA on wildtype mice and measured tick weight at day 3 post-attachment. We detected a significant increase in frequency of DETCs during a tick bite in the vamp33 siRNA treatment when compared to vamp33 scRNA control ticks (Fig. 4f). These results also agreed with our flow cytometry data showing the majority of $\gamma \delta$ T cells in the skin bitten by the tick were TCR $\gamma \delta^{\text {hi }}$ (Fig. $4 \mathrm{~g}$ ). Conversely, the predominant population of $\gamma \delta$ T cells in the draining lymph nodes were TCR $\gamma \delta^{\text {lo, }}$, which are non- $\mathrm{V} \gamma 5^{+} \mathrm{V} \delta 1^{+} \mathrm{T}$ cells. Altogether, these findings strengthened our argument that DETCs are the important $\gamma \delta \mathrm{T}$ cell subset in the skin during a tick bite.

Then, we investigated the effect of DETCs on tick feeding by placing ticks injected with vamp33 siRNA on FVB-Tac mice. FVB-Tac mice are naturally depleted of DETCs due to a failure of thymic selection because of a natural mutation of the skint 1 gene $^{52}$ (Fig. 4h, left-most rectangular bars). A decrease in weight was not observed when ticks deficient in EVs were placed on FVB-Tac (DETC depleted) mice (Fig. 4h, right-most rectangular bars). Conversely, we detected the opposite findings in FVB-JAX (DETC-sufficient) mice, which do not bear a mutation in the skint1 gene and harbored normal levels of DETCs. Collectively, we discovered that tick EVs regulate DETCs in the epidermis for an optimal feeding environment.

Intracellular bacteria manipulate the release of tick EVs during infection. As I. scapularis regulated host immunity, we examined whether intracellular bacteria altered the release of tick EVs upon infection. Accordingly, we detected a modified morphology and heterogeneity of EVs originating from tick cells previously infected with the intracellular rickettsial bacterium A. phagocytophilum, but not the extracellular spirochete $B$. burgdorferi (Fig. 5a and Supplementary Movies 10-12). Consistently, neither infection of tick cells with $B$. burgdorferi nor the human parasite Babesia microti substantially increased the secretion of EVs (Fig. 5b, Supplementary Fig. 10a, and Supplementary Movies 13 and 14). However, tick cells released more EVs in the classical exosomal range upon infection with the intracellular bacteria Ehrlichia chaffeensis and F. tularensis (Supplementary Fig. 10b, c and Supplementary Movies 15-18). Overall, we discovered that tick cells modify the production of EVs according to the intracellular bacterial lifestyle.

Oxidative stress has been recently linked to the pentose phosphate pathway (PPP) via the protein nuclear related factor 2 [NRF2 $]^{53}$. Previously, we indicated that cells change their oxidation state and produce reactive oxygen species during $A$. phagocytophilum infection ${ }^{54}$. We observed an enrichment of proteins from the PPP and the NRF2 signaling network in EVs derived from I. scapularis salivary glands (Fig. 5c, Supplementary Figs. 3 and 4, and Supplementary Data 2 and 4). Therefore, we asked whether the altered cargo content of tick EVs during bacterial infection could be related to the oxidation of protein side chains (e.g., carbonylation ${ }^{42}$ ). We incubated EVs from $I$. scapularis cell lines ISE6 and IDE12 with 2,4-dinitrophenylhydrazine (DNPH), which selectively binds to carbonyl groups ${ }^{55}$. Carbonylation present in tick EVs were then probed with an anti- 


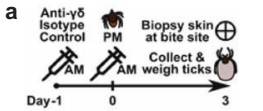

b

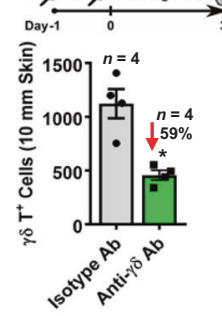

f
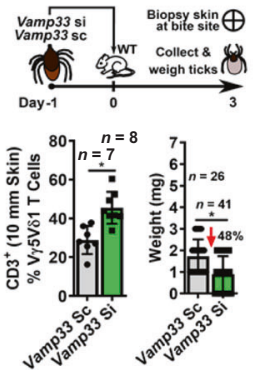

c

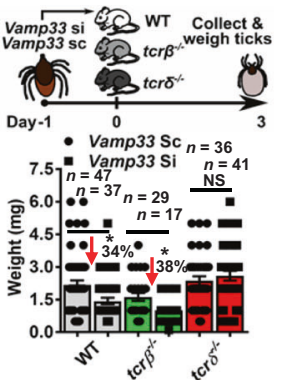

d

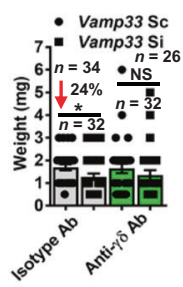

g

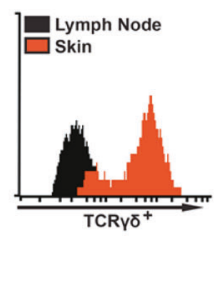

h

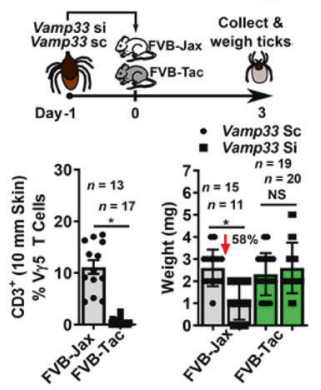

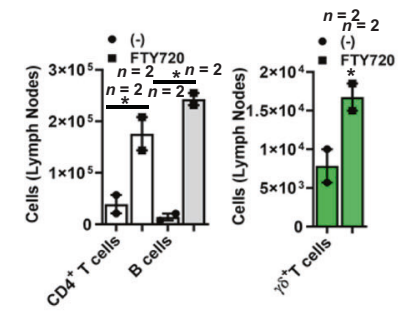

e

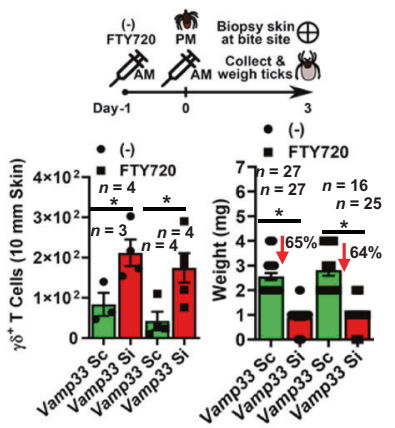

Fig. 4 Tick EVs affect DETCs in the murine skin. a Mice injected with anti- $\gamma \delta$ antibodies $(500 \mu g)$ display decreased $\gamma \delta$ T cells numbers at the skin site (right). The graph is representative of two independent experiments. b Vamp33 silencing (squares) resulted in similar tick bloodmeal intake when compared to the control treatment (circles) on $\gamma \delta$ T cell-depleted mice (green). The graph represents two independent experiments combined. $\mathbf{c} W$ eight of Vamp33 si or Vamp33 sc ticks placed on wild type (WT; gray), tcr $\beta^{-/-}$(green), and $\operatorname{tcr} \delta^{-/-}$(red) mice for 3 days. The graph represents four independent experiments combined. d Ticks were placed on FTY720-(squares) $(1 \mathrm{mg} / \mathrm{kg}$ ) or PBS-(circles) (-) treated C57BL/6 mice and allowed to feed for 3 days. Skin biopsies at the tick bite site and the draining lymph nodes were taken and immune cell populations were assessed by flow cytometry. The graph represents one of two independent experiments. e Vamp33 sc (green) or Vamp33 si (red) ticks were placed on PBS- (circles) (-) or FTY720- (squares)treated $(1 \mathrm{mg} / \mathrm{kg}$ ) C57BL/ 6 mice and their weight was measured three days post-infestation (two independent experiments combined). $\gamma \delta \mathrm{T}$ cell graph (left) represents one of two independent experiments. $\mathbf{f}$ Ticks were placed on C57BL/ 6 mice and allowed to feed for 3 days and their weight was measured (two independent experiments combined). Biopsies were taken from the tick bite site and the DETC $\left(\mathrm{V} \gamma 5^{+} \mathrm{V} \delta 1^{+}\right)$population was assessed by flow cytometry (one of two independent experiments). $\mathbf{g}$ Flow cytometry measurement of TCR $\gamma \delta^{\text {hi }}$ immune population in a murine skin sample when compared

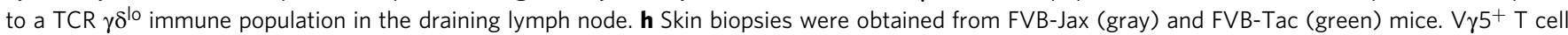
population was assessed by flow cytometry (two independent experiments). Vamp33 sc (circles) or Vamp33 si (squares) ticks were placed on FVB-Jax (gray) or FVB-Tac (green) mice. Tick weight measurement was obtained 3 days post-infestation (two independent experiments combined). Differences between treatments were evaluated with two-tailed Student's $t$ test for all data sets, except one-tailed in d. Statistical significance for all experiments are shown ${ }^{\star} p<0.05$; NS not significant, $n$ number of samples analyzed. Ab antibody, AM morning, PM afternoon. Source data are provided as a Source Data file. Mean \pm standard error of the mean (SEM) are plotted for all experiments except in $\mathbf{g}$.

DNPH antibody after derivatization. Interestingly, carbonylated proteins were detected in tick EVs at much higher levels in the $A$. phagocytophilum-infected treatment when compared to the control group (Fig. 5d, e). A similar effect was not observed for glycosylation (Fig. 5f) or phosphorylation (Fig. 5g). Collectively, we found out that the intracellular bacterial lifestyle modifies the cargo content and carbonylation within tick EVs.

Tick EVs enable distinct outcomes of bacterial infection in the mammalian host. We then asked whether tick EVs could affect microbial infection to the mammalian host. We tested this hypothesis by using two distinct models: (i) F. tularensis, which causes sepsis followed by death in mice ${ }^{56}$; and (ii) the mildly virulent rickettsial bacterium $A$. phagocytophilum, which does not cause lethality in mice ${ }^{54}$. We observed that $F$. tularensis injection via the intradermal route, which mimics tick infection, was fully virulent (Fig. 6a, b) ${ }^{56}$. Isolation of EVs from partially fed $D$. andersoni ticks, the vector of $F$. tularensis (agent of tularemia) in the western United States ${ }^{38}$, showed a heterogeneous EV population with an average mean size of $204 \pm 6 \mathrm{~nm}$ (Fig. 6c and Supplementary Movie 19). We then investigated whether EVs from $D$. andersoni ticks were protective against $F$. tularensisinduced sepsis. Mice injected with $D$. andersoni EVs and $F$. tularensis were more resistant to infection when compared to the control bacterial treatment (Fig. 6d, e). Mice injected with $D$. andersoni EVs and F. tularensis had also lessened splenomegaly (Fig. 6f) and decreased levels of interferon (IFN) $-\gamma$ and tumor necrosis factor (TNF)- $\alpha$ in the blood (Fig. $6 \mathrm{~g}$ and Supplementary Fig. 11a). Surprisingly, bacterial numbers were reduced in the liver and the spleen, but not the lungs of mice injected with $F$. tularensis and D. andersoni EVs (Fig. 6h, i and Supplementary Fig. 11b).

Finally, we developed an animal model of $F$. tularensis infection in mice using the tick $D$. variabilis. The intent was to determine whether injecting $10^{7}$ colony-forming units (CFU) of F. tularensis into mice was an experimentally judicious approach. This animal model of tick infection considered the 5-day blood meal of $D$. variabilis and the rapid lethality of $F$. tularensis. Surprisingly, $D$. variabilis harbored a very large amount of $F$. tularensis with an average of $9.5 \times 10^{5} \mathrm{CFU} /$ tick after repletion, to a high of $6.5 \times 10^{6} \mathrm{CFU} /$ tick of $F$. tularensis on week 4 postfeeding prior to molting (Fig. 6j). Following these results, we then assessed D. variabilis infection of $F$. tularensis in the laboratory onto naïve mice. Examination of mouse blood revealed that $100 \%$ of naïve mice were infected with $F$. tularensis on day 14 after tick placement (Fig. 6k). We observed high bacterial burdens in the blood $\left(6 \times 10^{5} \mathrm{CFU} / \mathrm{mL}\right)$, lungs, livers, and spleens $\left(3 \times 10^{5}-\right.$ $1.9 \times 10^{6} \mathrm{CFU} / \mathrm{mg}$ tissue). Importantly, our results corroborated with a reproducible and quantitative model of $F$. tularensis in $D$. variabilis ${ }^{57,58}$ and revealed that the presence of $F$. tularensis inside 
a
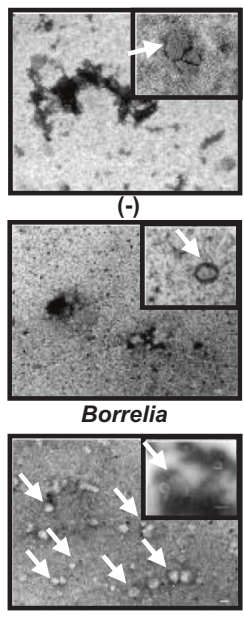

Anaplasma

C

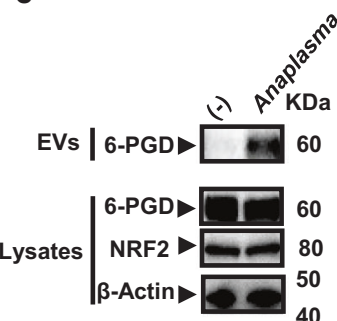

b

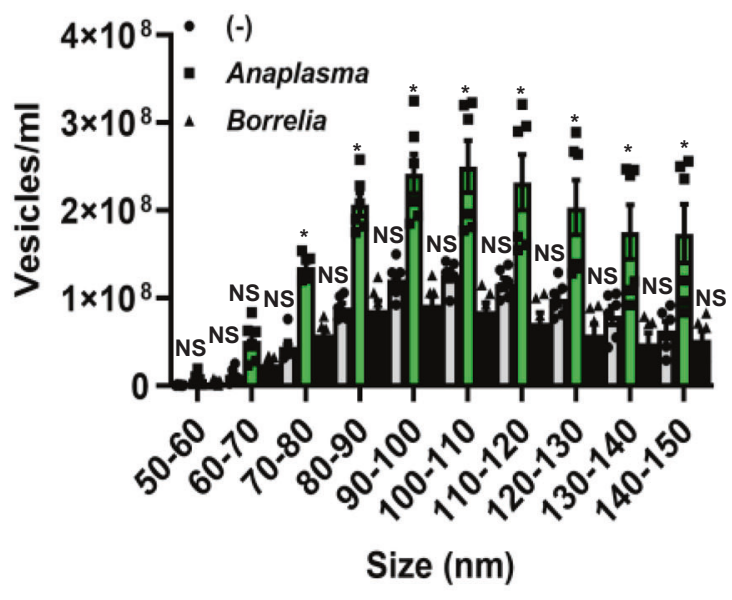

d

f
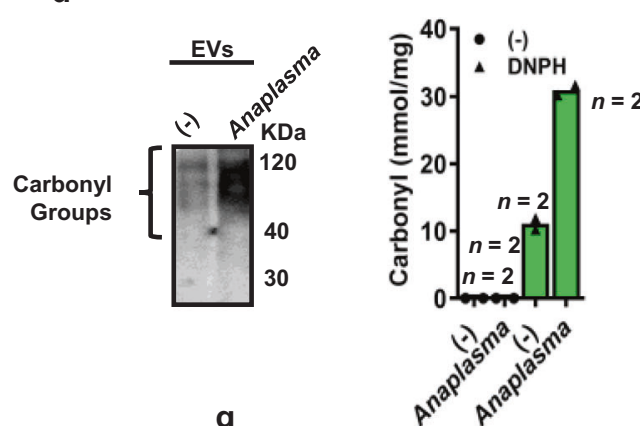

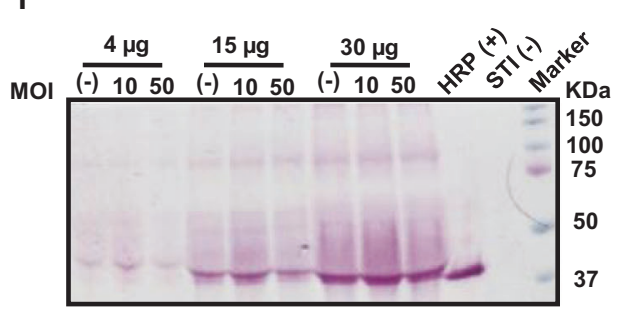

Glycosylation g

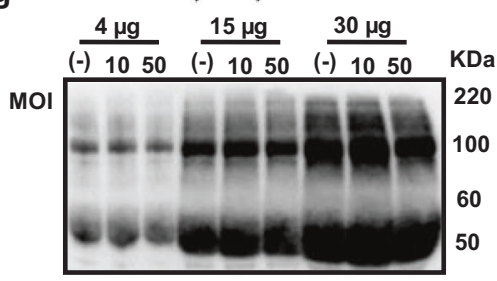

Phosphorylation (Serine)

Fig. 5 Tick EVs are modified by the intracellular bacterial lifestyle. a Transmission electron microscopy of EVs purified from I. scapularis ISE6 cells infected with A. phagocytophilum or B. burgdorferi. Scale bars: $100 \mathrm{~nm}$, large panel $=11,000 x$; small panel $=30,000 x$. The image is representative of two independent experiments. b I. scapularis EVs released from A. phagocytophilum or B. burgdorferi-stimulated ISE6 cells. Means \pm standard error of the mean (SEM) are plotted. $(-)$ unstimulated cells. $\left({ }^{*} p<0.05\right)$. Data is representative of three technical and two biological replicates. SDS-PAGE immunoblots showing increased release of c 6-phosphogluconate dehydrogenase (PGD) ( $50 \mu$ for lysates and $40 \mu$ for EV immunoblots, respectively); NRF2 nuclear factor erythroid 2-related factor 2. d $15 \mu \mathrm{g}$ of EVs derived from tick ISE6 cells infected with A. phagocytophilum (MOI 50) showing carbonylation. e Carbonylation in EVs derived from A. phagocytophilum-infected IDE12 cells (MOI 50; $15 \mu \mathrm{g}$ of EVs for ELISA). DNPH =2,4-dinitrophenylhydrazine. ( - ) represents uninfected ISE6 cells lysate. $\mathbf{f}, \mathbf{g}$ glycosylation and phosphorylation of proteins in uninfected and A. phagocytophilum-infected (MOI 10 and 50 ) EVs purified from tick ISE6 cells at indicated amounts. HRP $(+)$ represents the horseradish peroxidase positive control while STI (-) indicates the soybean trypsin inhibitor negative control. MOI multiplicity of infection. $\mathbf{f}, \mathbf{g}$ blots and gels were repeated at least twice obtaining the same results. Statistics in $\mathbf{b}$ was done by using Two-way ANOVA using size and treatment as variables followed by the post-hoc Sidak test for comparisons. $\left({ }^{\star} p<0.05\right)$. Source data are provided as a Source Data file.

ticks was comparable to what has been described on Martha's Vineyard ${ }^{59}$. Martha's Vineyard is an island off the coast of Massachusetts where epizootic transmission of tularemia by ticks has occurred since $2001^{60}$.

Opposite findings were observed when the mildly virulent bacterium A. phagocytophilum and I. scapularis EVs were injected intradermally into animals. I. scapularis EVs favored establishment of A. phagocytophilum to mice (Fig. 7a, b). No differences in cytokine release were observed between treatments during $A$. phagocytophilum infection (Fig. 7c, d). Collectively, our findings show that tick EVs distinctly regulate the infection of $A$. phagocytophilum and $F$. tularensis in the mammalian host during feeding.

\section{Discussion}

In most infectious diseases, the clinical outcome of an illness is determined primarily by interactions between the pathogen and the mammalian host. Nevertheless, for vector-borne diseases, ailment is not only driven by the arms race between the pathogen and the host, but also the arthropod. Currently, arthropod EVs are thought to enable pathogen transmission to mammals ${ }^{18,19}$. Here, we indicate that microbial infection mediated by arthropod EVs is more intricate than previously observed. Tick EVs promoted infection of the mild rickettsial agent A. phagocytophilum to the mammalian host. Conversely, tick EVs decreased $F$. tularensis morbidity and mortality in mice. Importantly, tick EVs 

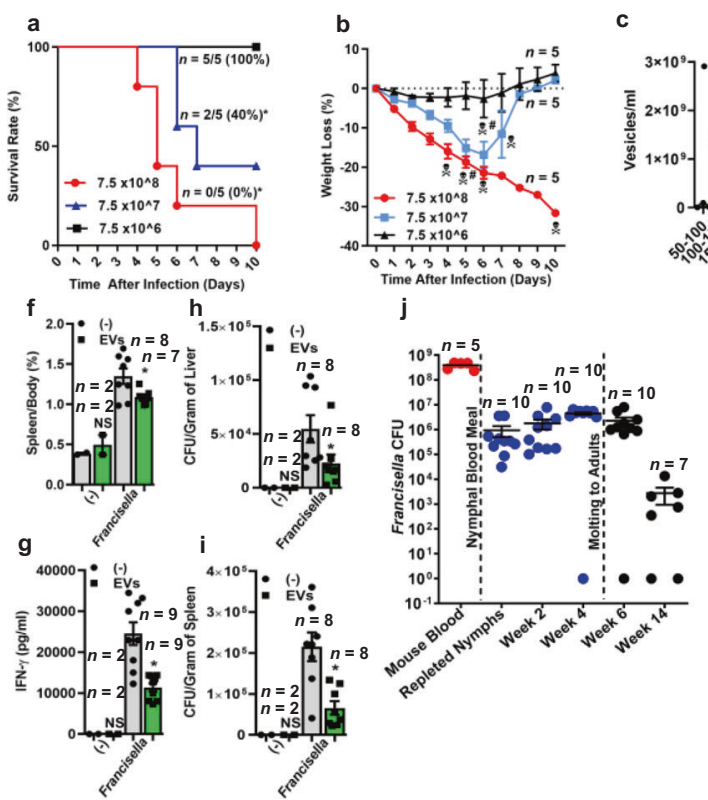

c

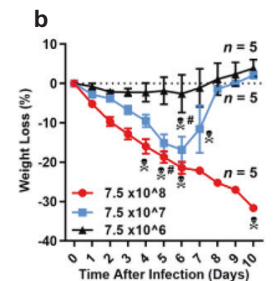

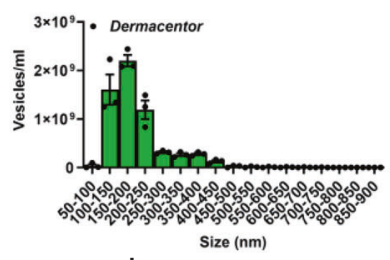

k
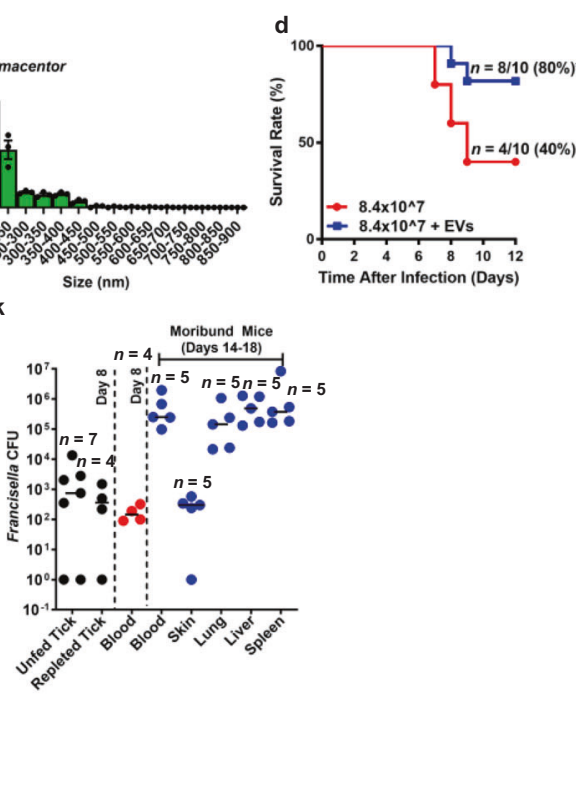

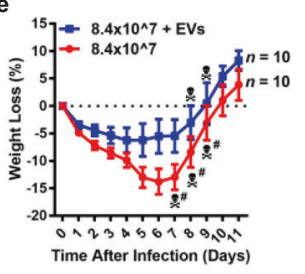

Fig. 6 D. andersoni EVs mitigate F. tularensis infection in the mammalian host. In a and $\mathbf{b}$ C57BL/ 6 mice were intradermally inoculated with three doses of F. tularensis live vaccine strain: $7.5 \times 10^{6}$ (black), $7.5 \times 10^{7}$ (blue), and $7.5 \times 10^{8}$ (red). Survival and loss of weight were monitored daily for 10 days. Data represents the mean \pm SEM; $n$ number of mice. c Quantity and size distribution of EVs purified from $D$. andersoni salivary glands, as judged by nanoparticle tracking analysis. Bars represent the standard error from three technical replicates. In d, e survival and weight loss in C57BL/6 mice inoculated with $8.4 \times 10^{7}$ CFU of $F$. tularensis co-injected with $1 \times 10^{8}$ D. andersoni EVs. EV treatment (blue); control (red). For e, data presents the mean $\pm \mathrm{SEM}$. In $\mathbf{f}-\mathbf{i} F$. tularensis ( $8 \times$ $10^{7} \mathrm{CFU}$ ) was co-injected in the presence (green) or absence (gray) of $D$. andersoni salivary gland EVs $\left(1 \times 10^{8}\right)$. $\mathbf{f}$ splenomegaly, $\mathbf{g}$ cytokine measurement made by a multiplex cytokine ELISA and $\mathbf{h}$, i plaque assays at day 5 post-infection. Data is presented as a mean and standard error of the mean ( \pm SEM). Statistical significance was determined using a two-tailed $t$ test of Francisella and Francisella + EVs. $\mathbf{f} p=0.03 ; \mathbf{g} p=0.0004 ; \mathbf{h} p=0.05 ; \mathbf{i} p=0.0017$. $\mathbf{j} D$. variabilis nymphs were placed onto naïve female $\mathrm{C} 3 \mathrm{H} / \mathrm{HeN}$ mice on day -5 and allowed to feed for three days. Mice were intravenously infected on day -2 with $1 \times 10^{7} \mathrm{CFU}$ of $F$. tularensis. Engorged (repleted) ticks and the mouse blood were collected 2 days later (day 0 ) and the CFU were obtained at indicated time points. The graph is representative of two independent experiments. $\mathbf{k}$ Infected adult $D$. variabilis ticks (week 14) were individually placed onto naïve mice to examine $F$. tularensis infection. Ticks completed their blood meal by day 8 and the mouse blood was harvested to quantitate bacterial numbers. Data is presented as mean. Five mice were monitored through day 18 with animals being euthanized when moribund. Skull and bones denote a single mouse death, whereas skull and bones with the pound sign indicates death of two mice. Survival was analyzed with the Kaplan-Meier curve. Statistical analysis was performed with the $\mathbf{a}, \mathbf{d}$ Log-rank (Mantel-Cox) or $\mathbf{f - i}$ the two-tailed $t$ test. In $\mathbf{b}$, e statistical analysis of weight data was not done due to the differential animal mortality during experiment. EVs extracellular vesicles, CFU colony-forming units. ${ }^{\star} p \leq 0.05$. NS not significant. Source data are provided as a Source Data file.

acted locally on skin immunity. The observation that tick EVs inhibited IFN- $\gamma$ and TNF- $\alpha$ in the mouse blood during F. tularensis infection was likely a consequence of molecular cues initiated at the skin site and distally propagated to other organs ${ }^{61}$. Furthermore, the effect of $D$. andersoni EVs in the spleen and the liver of mice injected with $F$. tularensis was an outcome of disease in our animal model.

Over the past century, researchers have debated the temporal kinetics of tick transmission of $F$. tularensis and the onset of tularemia in animal models ${ }^{62-64}$. Unfortunately, there is no consensus or universal approach that broadly describes the $F$. tularensis concentration inside the tick and in the saliva during transmission. Different tick infection techniques, environmental versus laboratory experiments, animal models, tick species, developmental stages, and Francisella genotype/strains lead to distinct experimental outcomes and disagreements among investigators. Thus, additional analysis will be required to determine the relevance of our findings in the natural habitat of ticks.

Correlative evidence suggested the role of SNARE proteins in arthropod feeding ${ }^{65-68}$. SNAREs are involved in the fusion of multivesicular bodies to the plasma membrane, releasing EVs into the extracellular milieu ${ }^{15-17}$. The scientific community has not yet firmly developed technical approaches to visualize and quantify EVs in vivo ${ }^{15,17}$. To date, only a few laboratories around the world have developed fluorescent proteins that are tagged to the plasma membrane to observe EVs in vivo by intravital microscopy or other sophisticated imaging techniques ${ }^{69,70}$. Additionally, these technologies are not yet viable in ticks because there are not any genome editing tools for I. scapularis ${ }^{39}$. Finally, tick feeding and salivation occur as an intermittent process for several days on a mammalian host ${ }^{71}$ and this uneven feeding activity changes the composition of molecules within the saliva $^{72,73}$. Thus, the quantification of EVs or microbial numbers secreted into the bite site during feeding are not feasible at this time. Given these impediments, we determined a reasonable number of EVs to use in our assays. Experimental approaches varied widely in the literature with EVs ranging from $10^{6}$ to $10^{8}$ molecules ${ }^{19,74-76}$. Hence, we concluded that the administration of $1 \times 10^{8} \mathrm{EVs}$ was a reasonable approach in our animal model.

The skin contains many immune cells that transport salivary antigens to the draining lymph nodes ${ }^{49}$. Most studies have portrayed the effects of the tick bite as taking place within the local feeding cavity and in the dermis ${ }^{4,49}$. However, an earlier study revealed antigens that may be trapped in the skin and affect an area beyond the dermal-epidermal location ${ }^{77}$. For I. scapularis, the effect of EVs was dependent on $\gamma \delta$ T cells. $\gamma \delta$ T cells act as a bridge between innate and adaptive immunity ${ }^{28-30}$ and are important against infection by tick-borne pathogens ${ }^{78,79} \cdot \gamma \delta$ $\mathrm{T}$ cells also detect tissue damage and are involved in wound repair ${ }^{28-30}$. We observed that inhibition of $\mathrm{EV}$ biogenesis in $I$. 

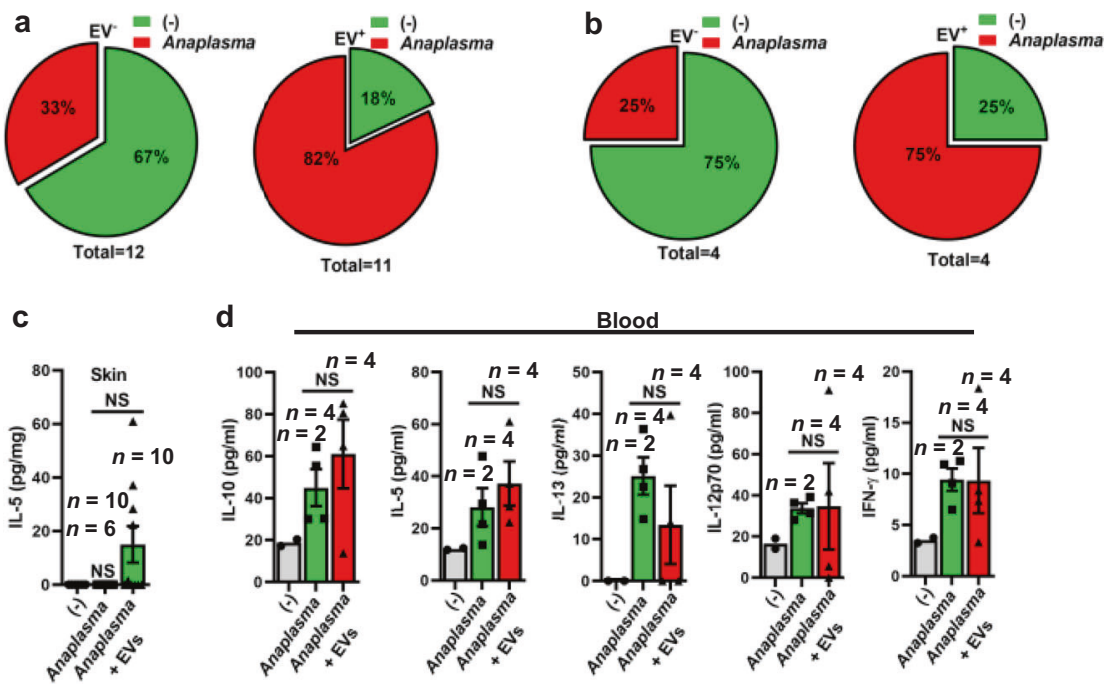

d

Blood

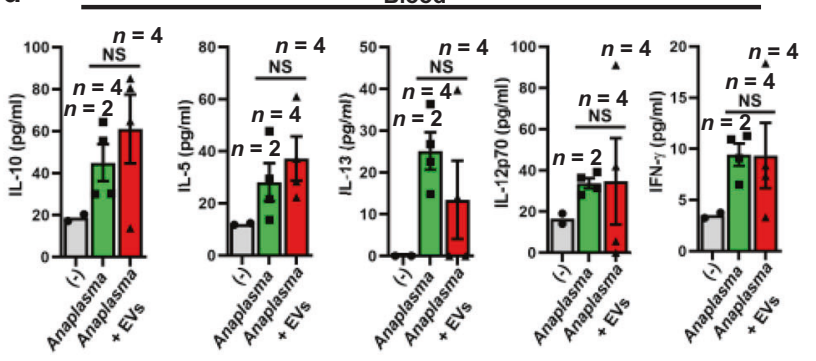

Fig. 7 I. scapularis EVs enable A. phagocytophilum infection in the mammalian host. A. phagocytophilum $\left(1 \times 10^{7}\right)$ was intradermally injected in the presence or absence of $I$. scapularis salivary gland EVs $\left(4 \times 10^{7}\right)$. The presence (red) or absence (green) of $A$. phagocytophilum in a skin or $\mathbf{b}$ spleen was measured by quantitative real-time PCR at day 3 post-infection. Cytokine measurements were done in the mouse $\mathbf{c}$ skin and $\mathbf{d}$ blood by a multiplex ELISA assay. Baseline treatment denotes skin and mouse blood without bacterial infection (gray bars). Data is presented as a mean and standard error of the mean $\left( \pm\right.$ SEM). ( ${ }^{*} p<0.05$; NS not significant). Graphs are representative of one in two independent experiments. Statistics in c were done by using oneway ANOVA, whereas $\mathbf{d}$ was done by two-tailed $t$-test between Anaplasma and Anaplasma + EVs. For $\mathbf{c} n=\operatorname{skin}$ samples and $\mathbf{d} n=b l o o d$ samples. Source data are provided as a Source Data file.

scapularis ticks resulted in a significant increase of $\gamma \delta$ T cells at the bite site. Remarkably, feeding has also been shown to reduce the number of circulating $\gamma \delta \mathrm{T}$ cells in animals infested with the ticks Haemaphysalis bispinosa and Hyalomma anatolicum ${ }^{80}$.

I. scapularis EVs affected DETCs, which are located in the mouse epidermis and important for wound healing ${ }^{28-30}$. DETCs interact with keratinocytes, which comprise of approximately $95 \%$ of all cells in the epidermal layer ${ }^{28}$. Forthcoming studies will ascertain whether tick EVs act directly on DETCs and also determine how DETCs affect cell intrinsic and extrinsic signaling in keratinocytes. For instance, tick EVs appear to change the molecular program of a human keratinocyte cell line ${ }^{41}$. Notably, we do not yet know whether the elongated dendrite morphology of DETCs enables contact with keratinocytes ${ }^{28,81}$ during a tick bite. Finally, investigators need to examine the cellular composition of the epidermis in DETC-deficient (FVB-Tac) and DETCsufficient (FVB-Jax) mice during a tick bite. FVB-Tac, but not the FVB-Jax mice, are depleted of DETCs because of an intrathymic differentiation defect due to a mutation in the skint1 gene ${ }^{52}$. Under normal conditions, DETCs interact with several neighboring cells in the epidermis. Conversely, the lack of DETCs in the epidermis results in increased keratinocyte death ${ }^{82}$ and repopulation of the epidermis by $\alpha \beta \mathrm{T}$ cells with a diverse $\mathrm{T}$ cell receptor repertoire ${ }^{28}$.

An ecological niche is comprised of biotic and abiotic factors that dictate interspecies relationships ${ }^{83}$. We showed that infection with three different tick-borne intracellular bacteria, A. phagocytophilum, F. tularensis, and to a lesser extent E. chaffeensis led to an increase in EV release and changes in their cargo content. This observation has also been described for arthropod-borne viruses $^{18,19}$; thus, this phenomenon appears to be an evolutionarily conserved mechanism. Previously, we discovered that infection with $A$. phagocytophilum increases oxidative stress ${ }^{54}$. Furthermore, a connection between inflammation and oxidative responses through the transcription factor $\mathrm{Nrf2}$ has been established ${ }^{53}$ and we observed that the accumulation of oxidized proteins elicits poor antigen presentation to $\mathrm{T}$ cells $\mathrm{s}^{55}$. We did not detect any differences in nrf2 expression in tick salivary glands infected with $A$. phagocytophilum. However, we observed an increased secretion of the Nrf2-regulated protein $6-\mathrm{PGD}^{53}$ in tick EVs. Whether the increase of 6-PGD in tick cells results from the parasitic or the mutualistic effects of $A$. phagocytophilum remains to be determined.

In summary, we used two bacterial models of infection (e.g., $A$. phagocytophilum and $F$. tularensis) to show that tick EVs promote distinct microbial outcomes in the mammalian host. Whenever possible, we recommend that arthropod vectors should be included in infectious disease studies due to their potential to modify the degree of pathogenesis in a microbe.

\section{Methods}

Reagents and resources. All primers, reagents, resources, manufacturers, and catalog numbers are listed in Supplementary Data 6 and 7.

EV-depleted medium. L15C300 medium was supplemented with 5\% fetal bovine serum (FBS; Millipore-Sigma), 5\% tryptose phosphate broth (TPB; BD), $0.1 \%$ lipoprotein concentrate (LPC; MP Biomedicals), $0.25 \%$ sodium bicarbonate $\left(\mathrm{NaHCO}_{3}\right.$; Millipore-Sigma), and $25 \mathrm{mM}$ HEPES (Millipore-Sigma) ${ }^{84}$. Medium was cleared from EVs by ultracentrifugation at $100,000 \times g$ for $18 \mathrm{~h}$ at $4{ }^{\circ} \mathrm{C}$ in a LE80 ultracentrifuge (Beckman Coulter) with a $60 \mathrm{Ti}$ rotor. DMEM medium supplemented with $10 \%$ FBS was also freed from EVs using the same method. The absence of EVs was confirmed by determining the particle size distribution with a Zetasizer NanoZS (Malvern Panalytical) or a NanoSight NS300 (Malvern Panalytical) for nanoparticle tracking analysis (NTA). EV-free medium was sterilized by passing the content through a 0.22 - $\mu \mathrm{m}$ Millipore Express ${ }^{\circledast}$ PLUS (MilliporeSigma).

Ticks. I. scapularis ticks were obtained from three independent sources: (1) the Centers for Disease Control and Prevention through the Biodefense and Emerging Infectious Diseases (BEI) Resources Repository; (2) Dr. Utpal Pal at the University of Maryland, College Park; and (3) Dr. Ulrike Munderloh and Dr. Jonathan Oliver at the University of Minnesota. Unfed nymphs and partially engorged adult female ticks were maintained in an I-30BLL incubator (Percival Scientific) at $25^{\circ} \mathrm{C}$ under saturated humidity $(>85 \%)$ in $16: 8 \mathrm{~h}$ light/dark cycle. D. variabilis ticks were

housed in 3-dram plastic vials in glass desiccators, with 12-h light-dark cycles, at ambient temperature over saturated potassium nitrate $\left(\mathrm{KNO}_{3}\right)$, which generates a humidified atmosphere of $>90 \%$ at $20^{\circ} \mathrm{C}$. D. andersoni ticks were received from the United States Department of Agriculture (USDA) - Agricultural Research Service (ARS). Partially engorged virgin females were dissected immediately upon arrival. 
Mice. Experiments were performed on C57BL/6J (WT), $c c r 2^{-/-}, \mathrm{ccr}^{-/-}$tcrdelta $^{-/-}$, tcrbeta $^{-/-} \mathrm{FVB} / \mathrm{N}$ Jax, and FVB/N Tac mice. Breeding pairs were purchased from the Jackson Laboratory except FVB/N Tac mice. FVB/N Tac mice were purchased from Taconic Biosciences. $\mathrm{C} 3 \mathrm{H} / \mathrm{HeN}$ mice, female, 8-10 weeks old, were purchased from Charles River and used for tick-F. tularensis experiments. All mouse strains were bred at the University of Maryland School of Medicine, unless otherwise indicated. Male mice (6-9 weeks) were used for tick feeding, chemokine and cytokine analysis, immune cell population assays, $\gamma \delta$ T cell antibody depletion, FTY720 treatment, and knockout experiments. Female mice (6-8 weeks) were used for bacterial infection experiments.

Cell lines. I. scapularis (ISE6), D. andersoni (DAE100), and A. americanum (AAE2) embryonic derived cell lines were obtained from Dr. Ulrike Munderloh at the University of Minnesota through a material transfer agreement. Tick cell lines were maintained in Cellstart $25 \mathrm{~cm}^{2}$ flasks (Greiner bio-one), containing L15C300 medium supplemented with 5\% FBS, 5\% TPB, and $0.1 \%$ LPC kept at $34{ }^{\circ} \mathrm{C}^{84}$. Bacterial infection experiments and subcultures were performed in whole $25 \mathrm{~cm}^{2}$ flasks (Greiner bio-one) when cells reached confluency, as evaluated by light microscopy with an AMG EVOS Fl digital inverted microscope (Thermo Fisher Scientific). HL-60 (CCL-240) cells were obtained from ATCC and grown in RPMI1640 medium with L-Glutamine (Quality Biological) supplemented with $10 \%$ FBS (Gemini Bio-Products) and 1\% GlutaMax ${ }^{\mathrm{TM}}$ (Gibco). DH82 cells were a kind gift from Jere McBride at University of Texas Medical Branch. These cells were grown in DMEM/F12 (1:1; Gibco) supplemented with 10\% FBS (Gemini Bio-Products). Both cell lines were maintained at $37^{\circ} \mathrm{C}$ and $5 \% \mathrm{CO}_{2}$. Cells numbers were determined using a TC20 $0^{\mathrm{m}}$ automated cell counter (Bio-Rad).

Microbial infection. A. phagocytophilum strain $\mathrm{HZ}$ was cultured in $75 \mathrm{~cm}^{2}$ flasks (CytoOne) containing HL-60 cells. Briefly, HL-60 cells were cultured in $20 \mathrm{ml}$ of RPMI medium, supplemented with 10\% Fetal Bovine Serum and 1x Glutamax. A. phagocytophilum infected cells $(500 \mu \mathrm{l})$ were added to $5 \mathrm{ml}$ of uninfected cells at 1 to $5 \times 10^{6}$ cells $/ \mathrm{ml}$ diluted in $24.5 \mathrm{ml}$ of media ${ }^{85}$. The percentage of infection was monitored by the Richard-Allan Scientific ${ }^{\mathrm{mu}}$ three-step staining (Thermo Fisher Scientific). Infected cells were spun onto microscope slides with a Cytospin 2 (Shandon). Cells were visualized by light microscopy with an Axioskop microscope (Zeiss). Bacteria were purified once cultures had reached $>70 \%$ infection. Bacterial numbers were estimated using the number of infected HL-60 cells $\times 5$ morulae/ cell $\times 19$ bacteria/cell $\times 0.5$ (representing $50 \%$ recovery rate) ${ }^{9}$. Infected cells were concentrated by centrifugation at $10,000 \times g$ for $5 \mathrm{~min}$. Cells and bacteria were resuspended in $5 \mathrm{ml}$ of L15C300 EV-free medium. Bacteria were isolated from cells through a $27-\mathrm{G}$ bent needle. Cell debris was separated from bacteria by centrifugation at $600 \mathrm{xg}$ for $10 \mathrm{mins}$. The supernatant was collected, and bacteria were then centrifuged at $10,000 \times g$ for 5 mins. Pelleted bacteria were resuspended in L15C300 EV-free media and inoculated into confluent ISE6 $25 \mathrm{~cm}^{2}$ flasks (Greiner bio-one) at a 50:1 MOI.

B. burgdorferi $\mathrm{B} 31$ strain, clone MSK $5^{86}$ was cultured in BSK-II supplemented with $6 \%$ normal rabbit serum (RS) until reaching mid-exponential phase. Bacteria were pelleted by centrifugation at $3000 \times \mathrm{g}$ for $15 \mathrm{~min}$ at $4^{\circ} \mathrm{C}$ and washed five times with 1x phosphate-buffered saline (PBS) to eliminate any remaining RS. Pelleted bacteria were resuspended in L15C300 EV-free media and inoculated into confluent layers of ISE6 cells at a MOI of 10:1. E. chaffeensis was cultured in DH82 cells ${ }^{87}$. DH82 cells were cultured in $75 \mathrm{~cm}^{2}$ flasks until $50-80 \%$ confluency and inoculated with $E$. chaffeensis DH82 infected cells (1:10). The percentage of infection was monitored by the Richard-Allan Scientific ${ }^{\text {mit }}$ three-step staining, as described for A. phagocytophilum. The number of bacteria was calculated using the same formula for A. phagocytophilum. Bacteria were purified by passing infected cells through a $27-\mathrm{G}$ bent needle and using the centrifugation steps previously described for A. phagocytophilum. Confluent AAE2 cells were inoculated with E. chaffeensis (MOI 50:1) in L15C300 EV-free medium.

Frozen stocks of $F$. tularensis LVS were obtained from Dr. Katharina Richard at the University of Maryland School of Medicine. Frozen stocks were thawed and diluted in L15C300 EV-free medium. DAE100 cells were inoculated with the diluted F. tularensis (MOI 10) in L15C300 EV-free medium. F. tularensis Type B strain LVS was also obtained from BEI Resources and cultured ${ }^{88}$. Blood from rag2 -/- mice infected with Babesia microti LabS1 strain was collected and diluted to $10^{5}$ infected red blood cells (iRBCs). iRBCs were inoculated into ISE6 cells $\left(4 \times 10^{7}\right.$ cells) flasks (Greiner bio-one) containing L15C300 EV-free medium. All tick cell line infections occurred for $18 \mathrm{~h}$ at $34^{\circ} \mathrm{C}$.

Tick salivary gland culture. Salivary gland EVs were purified from ex vivo cultures originated from partially engorged I. scapularis adult females and nymphs. Adult I. scapularis females were fed on 6-10-month-old female New Zealand white rabbits for 5-6 days at the CDC facilities and then shipped to the University of Maryland School of Medicine. For the nymph salivary gland culture, I. scapularis nymphs fed for 3 days on C57BL/6J (WT) mice. D. andersoni female adults fed on Holstein calves for a total of 6 days inside of stockinet sleeves. The stockinet sleeves were glued to the skin with a hip tag cement. Animals were stalled in moated blocks. After $24 \mathrm{~h}$, ticks were placed on the skin and allowed to feed for 5 days.
Partially-fed adult female ticks (25-69) and nymphs (15-30) were dissected 1-2 days post-removal. Ticks were dissected with $4 \mathrm{~mm}$ vannas scissors (Fine Science Tools) under a Stereo Zoom stereoscope (Bausch and Comb). In all, $10 \mu \mathrm{l}$ of PBS were added to samples to avoid desiccation. Midguts, Malpighian tubes, and other organs were removed. Salivary glands were dissected and cultured in 24-well cell culture plates (Corning). 10 salivary glands from adult ticks or 20 salivary glands from nymphs were placed in each well, containing $500 \mu \mathrm{l}$ of L15C300 EVfree medium supplemented with $1 \mathrm{x}$ penicillin/streptomycin (Corning) and $1 \mathrm{x}$ Amphotericin B (Gibco). Salivary glands were incubated for $24 \mathrm{~h}$ at $34^{\circ} \mathrm{C}$ to allow EV secretion.

To study the effect of intracellular bacteria on the content of salivary EVs, salivary glands (70-80) from adult female ticks (35-40) were dissected, as described above. Ten salivary glands were placed per well in vesicle-free medium supplemented with Amphotericin B (Gibco). Cell-free A. phagocytophilum was isolated and inoculated to the salivary cultures $\left(1.4 \times 10^{8}\right.$ bacteria/well). Salivary glands were incubated for $24 \mathrm{~h}$ at $34^{\circ} \mathrm{C}$ in the presence or absence of bacteria.

Tick saliva. Tick saliva was collected as described by Hackenberg et al. ${ }^{89}$. Briefly, fully fed Ixodes ricinus females (6-7 days) were fixed onto glass slides. Salivation was induced by applying $2 \mu \mathrm{l}$ of pilocarpine solution ( $33 \mathrm{~g} / \mathrm{l}$ in $96 \%$ ethanol; SigmaAldrich) to the tick dorsal scutum. Saliva was collected into capillary tubes placed around the hypostome of each tick. Ticks were maintained within a humidified chamber in sterile conditions at $37^{\circ} \mathrm{C}$ for $2-3 \mathrm{~h}$ during salivation. The saliva was pooled, filtered through a $0.22-\mu \mathrm{m}$ filter, and stored in $-80^{\circ} \mathrm{C}$ before being shipped to the University of Maryland School of Medicine.

EV purification. Medium collected from cell or salivary gland cultures were cleared of any live cells by centrifugation at $300 \times g$ for $10 \mathrm{~min}$ at $4^{\circ} \mathrm{C}$. Dead cells were removed by a second centrifugation at $2000 \times g$ for $10 \mathrm{~min}$ at $4^{\circ} \mathrm{C}$. The supernatant was collected, and apoptotic bodies were removed by a third centrifugation at $10,000 \times g$ for $30 \mathrm{~min}$ at $10^{\circ} \mathrm{C}$. To reduce the number of EVs $>200 \mathrm{~nm}$ in size, the supernatant was filtered through a $0.22-\mu \mathrm{m}$ Millipore syringe filter (MilliporeSigma). EVs were pelleted by ultracentrifugation $(100,000 \times g)$ for $18 \mathrm{~h}$ at $4{ }^{\circ} \mathrm{C}$. Supernatant was discarded and EVs were resuspended in PBS. Salivary EVs were purified using a protocol modified from Michael et al..$^{90}$ and Zlotogorski-Hurvitz et al..$^{91}$. In brief, tick saliva was centrifuged at $1500 \times g$ for $10 \mathrm{~min}$ at $4{ }^{\circ} \mathrm{C}$ to discard any cells present in the sample. The supernatant was collected and centrifuged for $20 \mathrm{~min}$ at $12,000 \times g$ at $4^{\circ} \mathrm{C}$. Following this procedure, the recovered material was diluted 1:1 in $1 \times$ PBS to reduce viscosity and centrifuged at $17,000 \times g$ for $15 \mathrm{~min}$ at $4{ }^{\circ} \mathrm{C}$. The supernatant was collected and the EVs were purified by ultracentrifugation at $100,000 \times g$ for $18 \mathrm{~h}$ at $4^{\circ} \mathrm{C}$. EVs were resuspended in RIPA buffer for western blotting.

Transmission electron microscopy. ISE6 cells were infected with either $A$. phagocytophilum or B. burgdorferi. EVs from equal number of infected or uninfected cells $\left(4.44 \times 10^{7}\right)$ were purified as described above and resuspended in PBS. EVs were further concentrated with Amicon ${ }^{\circledast}$ Ultra $0.5 \mathrm{ml}$ centrifugal filters $30 \mathrm{~K}$ (Millipore-Sigma). Samples were glow-discharged with 400 mesh formva-coated copper grids (Electron Microscopy Sciences) and negatively stained with $1 \%$ uranyl acetate (UA) or $1 \%$ sodium potassium phosphotungstate (PTA). Air-dried grids were examined in a Tecnai T12 transmission electron microscope (Thermo Scientific) at an operating voltage of $80 \mathrm{keV}$. Images were acquired using a bottom mount CCD camera (Advanced Microscopy Techniques) and AMT600 software (Advanced Microscopy Techniques). Transmission electron microscopy images were analyzed using ImageJ.

EV quantification. EV concentration and sizes were determined using the NanoSight LM10 or NS300 (Malvern Panalytical) machines with NTA software versions 2.0 or 3.0 , respectively. The mean of the size generated in the NTA reports was used to calculate the average size of the EVs in each sample. Data was analyzed using GraphPad Version 9.1.0 from Prism.

Proteomics of EVs. EVs from adult I. scapularis female salivary gland cultures were concentrated in L15C300 EV-free medium using a $300 \mathrm{kDa}$ Vivaspin500 filter (Sartorius). Concentrated EVs were re-suspended in 0.95 M sucrose (Sigma S0389) and applied on top of the following sucrose gradient: $2 \mathrm{M}, 1.65 \mathrm{M}, 1.3 \mathrm{M}, 0.95 \mathrm{M}$, $0.6 \mathrm{M}, 0.25 \mathrm{M}$ in a polypropylene ultracentrifuge tube. Samples were ultracentrifuged at $151,000 \times g$ for $16 \mathrm{~h}$ at $4{ }^{\circ} \mathrm{C}$. The first $750 \mu \mathrm{l}$ of the sample were removed from the top of the gradient as waste. The next two $1.5 \mathrm{ml}$ fractions were collected, washed with PBS, and ultracentrifuged for $70 \mathrm{~min}$ at $77,100 \times g$ at $4{ }^{\circ} \mathrm{C}$. Supernatant was removed and the pellet was processed.

$1 D$ SDS-PAGE and in-gel trypsin digestion. EV pellets were processed for proteomics analysis after fractionation on a $4-12 \%$ gradient NuPAGE ${ }^{\text {mt }}$ Bis-Tris gel (Invitrogen). Gel was stained with Silver Stain for Mass Spectrometry Kit (Pierce) and pieces of the gel were cut out, de-stained and washed. Gel pieces were reduced at $55^{\circ} \mathrm{C}$ for $1 \mathrm{~h}$ with $20 \mathrm{mM}$ DTT in $25 \mathrm{mM}$ ammonium bicarbonate buffer and alkylated for $50 \mathrm{~min}$ at room temperature in the dark with $55 \mathrm{mM}$ iodoacetamide 
in $25 \mathrm{mM}$ ammonium bicarbonate buffer. Proteins were digested with trypsin and Lys-C mix (Promega) at $37^{\circ} \mathrm{C}$ overnight. Following digestion, samples were evaporated to $100 \mu \mathrm{l}$ and desalted and concentrated with a C18 ZipTip (Millipore).

NanoLC-ESI-MS/MS analysis of tryptic/LysC peptides. Peptides were sequenced and analyzed by nanoLC-ESI-MS/MS using Qexactive HF quadrupole orbitrap mass spectrometers (Thermo Fisher Scientific), which was coupled to an Easy nLC 1000 UHPLC (Thermo Fisher Scientific) through a nanoelectrospray ion source. Peptides were separated on a C18 analytical column $(100 \mu \mathrm{m}$ internal diameter, $\times$ $20 \mathrm{~cm}$ length) packed with $2.7 \mu \mathrm{m}$ Phenomenex Cortecs particles. The solution of peptides was equilibrated with $3 \mu \mathrm{l} 5 \%$ acetonitrile $0.1 \%$ formic acid, before being separated using optimized 180 min linear gradients employing 2-32\% acetonitrile in a buffer with $0.1 \%$ formic acid, at a flow rate of $400 \mathrm{\eta l} / \mathrm{min}$. The LC mobile phase solvents and the sample dilutions contained $0.1 \%$ formic acid in water (Buffer A) and $0.1 \%$ formic acid in $100 \%$ acetonitrile (Buffer B) (Optima ${ }^{\text {mo }}$ LC/MS; Fisher Scientific). Data acquisition was performed using the instrument provided Xcalibur $^{\text {rt" }}$ (version 3.0) software. The mass spectrometer was operated in the positive ion ionization and data-dependent acquisition (DDA) mode. The full MS scans were obtained with a range of $\mathrm{m} / \mathrm{z} 300$ to 2000 , at a mass resolution of 120,000 at $\mathrm{m} / \mathrm{z}$ 200 , and a target value of $1.00 \mathrm{E}+06$ with the maximum injection time of $50 \mathrm{~ms}$. HCD collision was performed on the 15 most significant peaks, and tandem mass spectra were acquired at a mass resolution of 15,000 at $\mathrm{m} / \mathrm{z} 200$ and a target value of $1.00 \mathrm{E}+05$ with the maximum injection time of $110 \mathrm{~ms}$. The dynamic exclusion time was $20 \mathrm{~s}$. The normalized collision energy was optimized for $32-34 \%$.

Protein identification. Raw files were "de novo" sequenced and assigned with a protein ID using the Peaks 8.5/X+software (Bioinformatics Solutions, Waterloo, Canada) by searching against the "I. scapularis" genome in SwissProt database (January 2018; 21974 entries and updated December 2020 TrEMBL 62856 entries (38 reviewed by SwissProt). The following search parameters were applied for protein ID analysis: trypsin, Lys-C, as restriction enzymes and two allowed missed cleavages at both peptides ends. For the data acquired on QEHF, the parent mass tolerance was set to $15 \mathrm{ppm}$ using monoisotopic mass and the fragment ion mass tolerance was set to $0.05 \mathrm{Da}$. Carbamidomethyl cysteine $(+57.0215$ on $\mathrm{C})$ was specified in PEAKS 8.5/X + as a fixed modification. Methionine, histidine, and tryptophan oxidations $(+15.99$ on $\mathrm{MHW})$, deamidation of asparagine and glutamine (NQ-0.98), and pyro-Glu from glutamine (Q-18.01 N-term) were set as variable modifications.

To account for the possible redox stress induced post-translational modifications, we applied additional variable modification: Lys- $>$ Allysine $(-1.03$; K); Lys- $>$ Amino adipicAcid (+14.96; K); Amino (Y) (+15.01, Y); Trp->Oxolactone (W) (+13.98, W); Pro->Pyrrolidone (P) (-27.99; P); Pro->Pyrrolidinone (P) (-30.01; P); Arg->GluSA $(-43.05 ; \mathrm{R})$; Dehydrated 4-hydroxynonenal (HNE-Delta: $\mathrm{H}(2) \mathrm{O}(\mathrm{H}))(+138.21, \mathrm{C}, \mathrm{H}$, $\mathrm{K})$; reduced 4-Hydroxynonenal (HNE + Delta:H(2) $(\mathrm{H}))(+158.13, \mathrm{C}, \mathrm{H}, \mathrm{K})$; HNE $(+156.12, \mathrm{C}, \mathrm{H}, \mathrm{K})$; 4-Oxononenal $(\mathrm{ONE})(4-\mathrm{ONE})(+154.10, \mathrm{C}, \mathrm{H}, \mathrm{K})$; dehydrated 4Oxononenal Michael adduct (4-ONE + Delta: $\mathrm{H}(-2) \mathrm{O}(-1))(+136.09$; $\mathrm{C}, \mathrm{H}, \mathrm{K})$; Carboxymethylation (CML, CMA) $(+58.005 ; \mathrm{K}, \mathrm{R})$; and Carboxyethylation (CEL) $(+72.021 ; \mathrm{K}, \mathrm{R})$. Additional variable post-translational modifications were input during the searches to map possible changes in the signal transduction pathways involving phosphorylation (+79.97 on STYD), sulfation (+79.96 on TYS), ubiquiti nation $(+114.04$ on KST), and methylation $(+14.02$ on DEHST)

All MS data were first validated using the false discovery rate (FDR) method built in PEAKS $8.5 / \mathrm{X}+$ (which uses the decoy fusion method). Protein identifications were accepted if they could be assigned a confidence score $(-10 \operatorname{lgP})$ $>20$ and $(-10 \lg \mathrm{P})>20$ for peptides (corresponding to $p$-values $<0.01)$. The false discovery rate for proteins was further adjusted to $<3 \%$ after removing contaminants like keratins and allowing a minimum of 1 peptide per identified protein. An independent validation of the MS/MS-based peptides and protein identification was performed with the Scaffold (version Scaffold_4.6.2 and 4.10.0, Proteome Software Inc.) using the compatible ".mzid" files of each sample exported from PEAKS versions 8.5 and $\mathrm{X}+$. Peptide identifications were accepted if they could be established at $>90.0 \%$ probability by the Scaffold Local FDR algorithm. Protein identifications were accepted if they could be established at $>90.0 \%$ probability and contained at least 1 identified peptide. Protein probabilities were assigned by the Protein Prophet algorithm ${ }^{92}$. Proteins that contained similar peptides and could not be differentiated based on MS/MS analysis alone were grouped to satisfy the principles of parsimony. These settings ensured the attained $0.13 \%$ Decoy FDR for peptides and $0.7 \%$ FDR for proteins.

All proteins identified by 1 unique MS/MS and 1 unique peptide were further validated manually using the following criteria: (1) series of at least at least 3 or $4 b$ and $y$ ions, altogether covering more than $80 \%$ of the identified peptide sequence; (2) correct assessment of fragments due to the neutral loses of $\mathrm{H}_{2} \mathrm{O}(18 \mathrm{Da})$, carbonyl (CO) (28 Da) (i.e., " $a$ " ions for " $b$ " series) and loss of phosphates (98 Da for $\mathrm{H} 3 \mathrm{PO} 4$ and $80 \mathrm{Da}$ for HPO3); (3) correct assessment of internal fragments, mainly due to the presence of proline in the sequence. Proline residues normally fragment $\mathrm{N}$-terminal to the residue, producing fragments in either direction; (4) correct assignments for the $\mathrm{m} / \mathrm{z}$ and charge state of both the precursor and main a ' $b$ " and " $y$ " ions by inspecting the corresponding isotope envelopes. The MS/MS views together with the identified $a, b$ and $y$ ions were exported from PEAKS and are shown in the Supplementary Data 3 for all protein hits identified with at least 1 unique peptide.

Functional analysis. Proteins were annotated with GO terms from NCBI (downloaded on March 2016). Networks, functional analyses, and biochemical and cellular pathways were generated by employing the ingenuity pathway analysis (IPA; Ingenuity Systems) (Supplementary Data 5). For all IPA analysis, we used the identified proteins with their corresponding IDs presented in Supplementary Data 2. These molecules were overlaid onto a global molecular network provided by the Ingenuity Knowledge Base. The gene-ontology (GO) enrichment, networks and canonical pathways were then algorithmically generated based on their connectivity index using the built-in IPA algorithm. The probability of having a relationship between each IPA indexed biological function and the experimentally determined genes was calculated by a right-tailed Fisher's exact test with Benjamini-Hochberg multiple-testing correction. The level of significance was set to $p<0.05$. Accordingly, the IPA analysis identified the molecular and cellular pathways from the IPA library of canonical pathways that were most significant to the dataset $(-\log (p$ value $)>1.5)$.

EV populations. Proteins identified in I. scapularis salivary EVs were blasted against human homologs using PSI-BLAST (https://blast.ncbi.nlm.nih.gov). The gene code and protein ID were obtained for each tick protein, and their respective human homolog from Uniprot (https://www.uniprot.org/). These gene codes were used to determine to the enrichment of proteins from exosome and/or microvesicle origin by comparing the list of gene codes obtained from tick salivary vesicles with proteins reported in Vesiclepedia (http://microvesicles.org/\#) using FunRich (Functional and Enrichment analysis tool; http://funrich.org/index.html). Proteins that did not have human homologs or that their gene code was not recognized were not used for this analysis. Proteins that shared the same human homolog were included only once (Supplementary Data 4). The presence of markers for specific EV populations (Exo-S, Exo-L, and Exomeres) was determined by comparing the I. scapularis salivary EVs data set with the markers proposed elsewhere ${ }^{40}$.

Western blot analysis. Protein concentrations in EVs and cell lysates were determined with the Pierce ${ }^{\text {tw }}$ BCA Protein Assay kit (Thermo Fisher Scientific). To assess the enrichment of exosomal markers in tick EVs, vesicles were purified from uninfected or infected tick cell lines, salivary glands, and I. ricinus saliva, as described above. Proteins were electrophoresed in 4-15\% Mini-PROTEAN ${ }^{\circledR}$ TGX $^{n}$ precast gels (Bio-Rad) for $1.5 \mathrm{~h}$ at $100 \mathrm{~V}$ and transferred to $0.2 \mu \mathrm{m}$ PVDF membranes (Trans-blot ${ }^{\circledR}$ Turbo $^{\mathrm{m}}$ transfer pack; Bio-Rad) for $30 \mathrm{~min}$ in a TransBlot ${ }^{\circledR}$ Turbo $^{\text {(T) }}$ transfer system (Bio-Rad). Membranes were blotted in 5\% dry-milk in PBS for $1 \mathrm{~h}$ at RT. Membranes were incubated with anti-TSG101 (1:500 dilution; System Biosciences EXOAB-TSG101-1), -CD63 (1:500 dilution; System Biosciences EXOAB-CD63A-1), -ALIX (1:500 dilution; System Biosciences EXOAB-ALIX-1), -SL2 (1:500 dilution), -Calnexin (1:10,000 dilution; Millipore-Sigma AB2301),

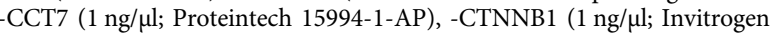

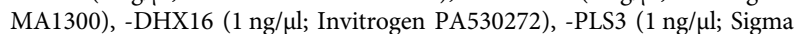

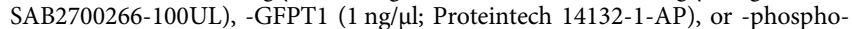
serine ( $1 \mathrm{ng} / \mu \mathrm{l}$; Abcam ab9332-100 $\mu \mathrm{g})$ antibodies overnight at $4^{\circ} \mathrm{C}$. Bands were detected by incubating the membrane with anti-rabbit (Novex A16023) or mouseHRP-conjugated antibodies (Abcam ab99632; 1:4000) for $1 \mathrm{~h}$ at RT, labeled with Pierce ${ }^{\circledR}$ ECL Western Blot Substrate (Thermo Fisher Scientific) and visualized with a ChemiDoc ${ }^{\mathrm{mm}}$ MP (Bio-Rad). Images of the blot were acquired with Image Lab Software version 5.0 (Bio-Rad). Equal numbers of ISE6 cells $\left(3.46 \times 10^{7}\right.$ cells) were infected with either A. phagocytophilum or B. burgdoferi. Proteins were run in western blots.

EV glycosylation assays. EVs were purified from partially engorged I. scapularis salivary glands and uninfected or A. phagocytophilum (MOI 10 and 50)-infected tick ISE6 and IDE12 cells. Protein concentrations in EVs were determined with the Pierce $^{\mathrm{mt}}$ BCA Protein Assay kit (Thermo Fisher Scientific). Proteins were loaded at an equal amount and electrophoresed in $4-15 \%$ Mini-PROTEAN ${ }^{\circledR}$ TGX $^{\mathrm{N}}$ precast gels (Bio-Rad) for $1.5 \mathrm{~h}$ at $100 \mathrm{~V}$ followed by glycosylation assay with Pierce Glycoprotein Staining Kit (Thermo Fisher Scientific).

\section{EV oxidation assays}

Western blot. Carbonylated proteins within tick EVs were detected using the OxiSelect $^{\text {tu }}$ Protein Carbonyl Immunoblot kit (Cell Biolabs STA-308-T). EVs from partially engorged I. scapularis salivary glands and uninfected or Anaplasma (MOI 10 and 50)-infected tick ISE6, and IDE12 cells were purified and resuspended in PBS. Protein concentrations were measured with the Pierce BCA Protein Assay Kit. Equal amounts of protein $(15$ or $30 \mu \mathrm{g}$ ) were loaded onto $4-15 \%$ Mini-PROTEAN TGX $^{\text {it }}$ precast gels, electrophoresed for $1.5 \mathrm{~h}$ at $100 \mathrm{~V}$, and transferred into $0.2 \mu \mathrm{m}$ PVDF membranes (Trans-blot ${ }^{\oplus}$ Turbo $^{\text {mit }}$ transfer pack) for 30 min at $25 \mathrm{~V}-1.0 \mathrm{~A}$ in a TransBlot $^{\circledR}$ Turbo $^{\text {rw }}$ transfer system. Membranes were submerged into $100 \%$ methanol, dried for $5 \mathrm{~min}$ at RT, equilibrated in Tris Buffered Saline (TBS) with $20 \%$ methanol (Millipore-Sigma) for $5 \mathrm{~min}$, and washed in $2 \mathrm{~N} \mathrm{HCl}$ for $5 \mathrm{~min}$, as recommended by the manufacturer. The membrane was then incubated in $1 \mathrm{x}$ $\mathrm{DNPH}$ in $2 \mathrm{~N} \mathrm{HCl}$ for $5 \mathrm{~min}$ at RT and washed three times in $2 \mathrm{~N} \mathrm{HCl}$ for $5 \mathrm{~min}$. 
The DNPH and non-DNPH (control)-treated membranes were blotted in 5\% drymilk in PBS-T for $1 \mathrm{~h}$ at RT. Carbonylated proteins were detected with rabbit antiDNP antibodies (1:1000) for $2 \mathrm{~h}$ at RT and with anti-Rabbit-HRP-conjugated antibodies (1:1000) for $2 \mathrm{~h}$ at RT.

ELISA. We purified EVs from $4.10 \times 10^{7}$ uninfected and A. phagocytophiluminfected ISE6 cells. Protein carbonylation was confirmed using the OxiSelect ${ }^{\text {tw }}$ Protein Carbonyl ELISA kit (Cell Biolabs STA-310). Protein concentrations were measured with the Pierce BCA Protein Assay Kit. In all, $1 \mu \mathrm{g}$ of protein per well was loaded into a 96-well plate and allowed to bind overnight at $4{ }^{\circ} \mathrm{C}$. Wells were washed three times with 1x PBS and 1x DNPH working solution, incubating the wells for $45 \mathrm{~min}$ at RT. Wells were washed five times with 1:1 ethanol:PBS and two times with $1 \mathrm{x}$ PBS. Wells were then blocked for $2 \mathrm{~h}$ at RT and washed, following the manufacturer's recommendations. Anti-DNP antibodies were added to each well and the plate was incubated for $1 \mathrm{~h}$ at RT under constant shaking. After three washes, HRP-conjugated antibodies were added to each well and incubated for $1 \mathrm{~h}$ at RT. Wells were washed five times and protein carbonylation was detected with $1 \mathrm{x}$ substrate solution. The reaction was blocked by adding $100 \mu \mathrm{l}$ of the stop solution and absorbance was read in an iMark microplate reader at $450 \mathrm{~nm}$ (BioRad).

PGD and NRF2 western blots. Vesicle blots were probed with anti-NRF2 (GeneTex GTX55732; 1:1000) and anti-PGD (Thermo Fisher Scientific PA5-27486; 1:1000) polyclonal antibodies. Bands were stained as described above.

\section{Macrophage differentiation}

Murine. Bone marrow-derived macrophages (BMDMs) were generated from $\mathrm{C} 57 \mathrm{BL} / 6 \mathrm{~J}$ mice ${ }^{40}$. In brief, mice were euthanized using $\mathrm{CO}_{2}$ and femurs were dissected. Bone marrow was flushed by injecting differentiating medium consisting of DMEM supplemented with 30\% L929 condition medium, 10\% FBS (Gemini Bio-products), 1x penicillin/streptomycin (Corning), and 1x Amphotericin B (Gibco) into one end of the femur with a $25 \mathrm{G}$ needle. Cells were seeded onto $90 \mathrm{~mm}$ Petri dish plates and incubated at $37^{\circ} \mathrm{C} 5 \% \mathrm{CO}_{2}$. Additional differentiating medium was added to cells on day 3 after seeding. Cells were incubated for 7 days until completely differentiated.

Human. Human macrophages were differentiated from peripheral blood mononuclear cells (PBMCs) as described in Noel et al..$^{93}$. Briefly, human blood was obtained from healthy adult volunteers. PBMCs were purified from $10 \mathrm{ml}$ of EDTA-treated human blood using Ficoll-Paque PREMIUM density $1.007 \mathrm{~g} / \mathrm{ml}$ (GE Healthcare). Contaminating red blood cells were lysed with ACK lysis buffer for $5 \mathrm{~min}$ at room temperature (RT). Monocytes were enriched by negative selection using the human Pan Monocyte Isolation Kit (Miltenyibiotec) and LS Columns (Miltenyibiotec). Monocytes were resuspended in RPMI supplemented with $10 \%$ FBS (Gemini Bio-products), $55 \mu \mathrm{M}$ 2-Mercaptoethanol (Gibco), $1 \mathrm{mM}$ Sodium Pyruvate (Gibco), 1x MEM non-essential amino acids (Gibco), and 1x penicillin/ streptomycin (Corning). Cells were counted using Trypan blue stain $(0.4 \%$; Thermo Fisher Scientific) in a TC20 $0^{\mathrm{mot}}$ Automated cell counter (Bio-Rad) and $2 \times$ $10^{6}$ monocytes were seeded into six-well plates (Sigma). Human recombinant Macrophage Colony-Stimulating Factor (M-CSF; Biolegend) was added to each well at $50 \mathrm{\eta g} / \mathrm{ml}$ final concentration on days 0,2 , and 4 after seeding. Medium was changed on day 4 . Cells were incubated at $37^{\circ} \mathrm{C} 5 \% \mathrm{CO}_{2}$ for 6 days to allow differentiation into M0 macrophages.

\section{EV labeling}

PKH26 staining. Tick cell EVs were stained as described in van der Vlist et al. ${ }^{94}$. Staining solution was prepared by mixing $1.5 \mu \mathrm{l}$ of PKH26 with $100 \mu \mathrm{l}$ diluent $\mathrm{C}$ in a microcentrifuge tube. PKH26 is a red fluorescent dye with long aliphatic tails ${ }^{45}$. In Fig. 2c, g, PKH26 was artificially transformed to an orange color to be visualized by color-blind readers. EVs $(5 \mu \mathrm{g})$ were resuspended in $20 \mu \mathrm{l}$ of $0.2 \%$ BSA in PBS precleared of protein aggregates by overnight ultracentrifugation at $100,000 \times g$ at $4{ }^{\circ} \mathrm{C}$ and diluted into $80 \mu \mathrm{l}$ diluent C. EVs were transferred to the staining mix, mixed by pipetting, and incubated at RT for $3 \mathrm{~min}$. The labeling was stopped by adding $100 \mu \mathrm{l}$ phenol red-free IMDM. Protein aggregates and extra dye was separated from the labeled EVs with a $300-\mathrm{kDa}$ Vivaspin500 filter (Sartorius). EVs were washed three times with IMDM and resuspended in phenol red-free IMDM.

$\mathrm{DiO}$ staining. Tick cell EVs were labeled by adding 2.5-5 $\mu \mathrm{l}$ of Vibrant $\mathrm{DiO}$ celllabelling solution (Invitrogen) to $480 \mu \mathrm{g}$ of EVs in $500 \mu \mathrm{l}$ of EV-free DMEM medium and incubated for $20 \mathrm{~min}$ at $37^{\circ} \mathrm{C}$. Excess label and protein aggregates were cleared through a $300-\mathrm{kDa}$ Vivaspin500 filter (Sartorius). EVs were washed three times with EV-free DMEM and resuspended in $150 \mu \mathrm{l}$ of EV DMEM medium.

\section{EV-macrophage interactions}

Confocal microscopy. BMDM and human macrophages were isolated as described above. Cells $\left(3 \times 10^{5}\right)$ were seeded onto $35 \mathrm{~mm}$ glass bottom dishes (MatTek Corporation) and allowed to attach overnight. Medium was replaced using phenol red-free, EVs-free DMEM medium and $5 \mu \mathrm{M}$ Cytochalasin D (Santa Cruz
Biotechnology). Cells were incubated for $30 \mathrm{~min}$ at $37^{\circ} \mathrm{C}$ under $5 \% \mathrm{CO}_{2}$. $\mathrm{PKH} 26$ labeled EVs ( $25 \mu \mathrm{g} / \mathrm{MatTek})$ were added after incubation with Cytochalasin D and cells were incubated for $4-5 \mathrm{~h}$ at $37^{\circ} \mathrm{C}$ under $5 \% \mathrm{CO}_{2}$ to allow binding. Control cells did not receive EVs. Cell plasma membrane was labeled with CellMask ${ }^{\mathrm{m}} \mathrm{Green}$ plasma membrane stain $\left(1: 1000\right.$; Invitrogen) at $37^{\circ} \mathrm{C}$ for $5 \mathrm{~min}$. The medium was replaced with phenol red-free, EV-free DMEM medium containing $5 \mu \mathrm{M}$ Cytochalasin D. Z-stacked images were acquired with a LSM 5 Live DUOScan laser scanning microscope (Zeiss). Composites were constructed using ImageJ (NIH) Z projection (maximum intensity).

Live-cell confocal microscopy. BMDMs were seeded and treated as described above. Cells were labeled with CellMask ${ }^{\mathrm{mm}}$ Green plasma membrane stain (Invitrogen). Medium was replaced with phenol red-free, EV-free DMEM medium containing 5 $\mu \mathrm{M}$ Cytochalasin D. Cells were placed in an external unit and kept at $37^{\circ} \mathrm{C}$ under $5 \% \mathrm{CO}_{2}$. Z-stacked images were acquired every $5 \mathrm{~min}$ for $2 \mathrm{~h}$ with a LSM 5 Live DUOScan laser scanning microscope (Zeiss). Twenty-five $\mu$ g of PKH26-labeled EVs were added after time 0 for the positive control. No EVs were added to the negative controls. Z-projections (maximum intensity) of each channel and videos of the $\mathrm{Z}$ projections were constructed in ImageJ at 2 frames-per-second (fps). Arrows were added with Windows Video Maker (Windows).

Time-lapse live-cell microscopy. BMDMs were seeded and labeled with CellMask ${ }^{n}$ green plasma membrane stain (Invitrogen). After 5-min staining, the medium was replaced with phenol red-free, EVs-free DMEM medium, and the MatTek flask was placed into a Viva View FL incubator (Olympus) at $37^{\circ} \mathrm{C}$ under $5 \% \mathrm{CO}_{2}$. $\mathrm{PKH} 26-$ labeled EVs $(40 \mu \mathrm{g})$ were added before collecting images. Images were acquired with an Orca $\mathrm{R}^{2}$ digital CCD camera (Hamamatsu) and the MetaMorph software every $5 \mathrm{~min}$ for $7 \mathrm{~h}$. Images were grouped into stacks using ImageJ for each fluorescence channel. The change in the arbitrary fluorescence units (AFU) was measured with ImageJ, as follows: cells (7 positions) were chosen using the "freehand selection" in the green channel. Cell selection was moved to the red channel using the "ROI manager". The increase in red fluorescence was measured with the "Plot Z-axis Profile" option. The same procedure was repeated with 7 positions close to the cells to measure the fluorescence in the background. The "Raw Intensity" of the background was subtracted from the "Raw Intensity" of the cell for each time point. The resulting "Raw Intensity" of each time point was normalized by the "Raw Intensity" at time 0 to account for differences in background between the control and other samples.

Flow cytometry. BMDMs and human macrophages were differentiated, as described above. Differentiated macrophages were resuspended in EV-free DMEM medium and aliquoted into microfuge tubes. Cells $\left(5 \times 10^{5}\right)$ were incubated with $40 \mu \mathrm{g}$ of DiO-labeled EVs, $40 \mu \mathrm{g}$ of unlabeled EVs, a combination of $20 \mu \mathrm{g}$ of DiO-labeled and $20 \mu \mathrm{g}$ of unlabeled EVs, or no EVs for $45 \mathrm{~min}$ at $37^{\circ} \mathrm{C}$ under $5 \% \mathrm{CO}_{2}$. Cells were centrifuged at $300 \times g$ for $10 \mathrm{~min}$ to eliminate unbound EVs. Macrophages were resuspended in $250 \mu \mathrm{l}$ of EV-free DMEM medium and labeled with either APC-labeled anti-mouse F4/80 antibodies (Invitrogen MF48005; 1:100) or APC/ Cy7-labeled anti-human CD11b (Biolegend 301341; 1:100) and APC anti-human CD14 (eBioscience $17-0149-41 ; 1: 100$ ) for $30 \mathrm{~min}$ at RT. Three replicates were left unlabeled as controls. Excess antibody was eliminated by centrifuging at $300 \times \mathrm{g}$ for 10 min and resuspending cells in 1\% paraformaldehyde in PBS. Cell fluorescent labeling was analyzed using a LSR II (BD Biosciences). Data was analyzed with FCS Express 6 Flow Research Edition (De Novo Software). Experiments were performed in the Flow and Mass Cytometry Core Facility of the University of Maryland School of Medicine Center for Innovative Biomedical Resources (CIBR).

RNAi silencing. Tick homologs of proteins involved in exosome biogenesis in human cells (Supplementary Data 1) were determined using PSI-BLAST. These homologs were used to re-construct the exosome biogenesis pathway in the $I$. scapularis genome. Small interfering RNAs (siRNAs) and scramble RNAs (scRNAs) were designed for two v-SNARES, synaptobrevin 2 (vamp2) and vamp33 (NCBI reference in Supplementary Data 6). Silencing (Si)RNAs were designed using BLOCK-iT ${ }^{\text {tw }}$ RNAi designer (http://rnaidesigner.thermofisher.com/ rnaiexpress/). Scramble (Sc) RNA was designed using GenScript (https://www. genscript.com/tools/create-scrambled-sequence). Both Si and ScRNAs were blasted against the I. scapularis genome to avoid off-target effects and synthesized according to the Silencer ${ }^{\circledast}$ SiRNA construction kit (Thermo Fisher Scientific). Primers are described in Supplementary Data 6.

In vitro silencing. ISE6 $\left(\sim 2 \times 10^{7}\right)$ cells were placed in $25 \mathrm{~cm}^{2}$ flasks and transfected with $30 \mu \mathrm{g}$ of SiRNA or ScRNA against synaptobrevin 2 or vamp33 diluted in $500 \mu \mathrm{l}$ of normal L15C300 medium, and $25 \mu$ Lipofectamine 2000 (Thermo Fisher Scientific) diluted in $475 \mu \mathrm{l}$ normal L15C300 medium (1:40). Cells were incubated with the transfection agent for $24 \mathrm{~h}$ at $34^{\circ} \mathrm{C}$ and medium was replaced by EV-free medium. Cells released EVs for $18 \mathrm{~h}$ at $34^{\circ} \mathrm{C}$. EVs were purified as described above. The viability of cells was measured using Trypan blue stain. EV concentration was measured using NTA. After silencing, cells were pelleted and resuspend in $2 \mathrm{ml}$ $\mathrm{TRIzol}^{\circ}$ reagent (Thermo Fisher Scientific) and stored at $-80^{\circ} \mathrm{C}$ until RNA isolation. RNA was isolated from $600 \mu \mathrm{l}$ of the TRIzol suspension using PureLink ${ }^{\mathrm{m}}$ 
RNA mini kit (Thermo Fisher Scientific). RNA was measured using a NanoDrop Spectrophotometer ND-1000 (Thermo Fisher Scientific). cDNA was synthesized from 150 to $400 \eta \mathrm{g}(5 \mu \mathrm{l})$ of RNA using Verso cDNA synthesis kit (Thermo scientific).

In vivo silencing. Unfed nymphs were microinjected with 50-80 $\eta \mathrm{g}$ of Si or ScRNA against synaptobrevin 2 or vamp33 using a Nanoject III (Drummond Scientific Company). Ticks recovered overnight at $25^{\circ} \mathrm{C}$ with saturated humidity. Live ticks were placed on mice and allowed to feed for 3 days. Ticks were stored at $-80^{\circ} \mathrm{C}$ for RNA purification. To purify mRNA, ticks were fast-frozen in liquid nitrogen and crushed with small plastic pestles. TRIzol ${ }^{\circledast}$ reagent $(200 \mu \mathrm{l})$ was added to the crushed tick and RNA was purified using the PureLink ${ }^{\mathrm{m}}$ RNA mini kit. cDNA was synthesized from 50 to $200 \eta \mathrm{g}$ ( $5-10 \mu \mathrm{l})$ of RNA using Verso cDNA synthesis kit (Thermo scientific).

Gene expression. Primers to determine the expression levels of synaptobrevin 2, vamp33, and I. scapularis actin (Supplementary Data 6) were designed using Geneious R10 (Biomatters Inc.) and checked for specificity with Primer BLAST (https://www.ncbi.nlm.nih.gov/tools/primer-blast/). Standard curves were produced using the $\mathrm{pCR}^{4} 4$ plasmid. To determine copy numbers, the mass of the plasmid with each amplicon was determined using the Sequence Manipulation suite DNA molecular weight (http://www.bioinformatics.org/sms2/dna_mw.html) and the copy number calculator (http://scienceprimer.com/copy-number-calcu lator-for-realtime-pcr). Levels of gene expression were measured by absolute quantification using Power SYBR ${ }^{\Phi}$ Green PCR master mix (Thermo Fisher Scientific) and normalized to the expression of tick actin. Amplifications were done using the following conditions: a denaturation cycle of 10 mins at $95^{\circ} \mathrm{C}$, followed by 40 cycles of denaturalization for $15 \mathrm{~s}$ at $95^{\circ} \mathrm{C}$, amplification at two different annealing temperatures (synaptobrevin and vamp33: $51^{\circ} \mathrm{C}$; tick actin: $57^{\circ} \mathrm{C}$ ) for 1 min. Primers were used at a final concentration of $400 \eta \mathrm{M}$ each and $2 \mu \mathrm{l}$ of cDNA were used as template. The specificity of the products was determined by single peaks in the melting curves. Quantitate PCR was collected in the Applied Biosystems 7500 Fast Real-Time PCR System through the 7500 Software v2.3.

Weight measurements. Ticks were microinjected with silencing RNA (vamp33 si and synap $2 s i)$ or scramble RNA (vamp33 $s c$ and synap $2 s c$ ). Surviving ticks were placed on C57BL/6 J (WT), FVB/N Jax, FVB/N Tac, or knockout mice to feed for 3 days. Ticks were recovered from a water trap (fully engorged) or were removed with forceps (partially engorged). The percentage of attachment was calculated from the total number of ticks recovered divided by the total number of ticks applied. The weight of the ticks was measured using a Pioneer ${ }^{\mathrm{mt}}$ analytical balance (OHAUS) and the differences in engorgement were evaluated.

Inflammation at the bite site. To determine the degree of inflammation at the bite site, skin samples were taken from mice infested with I. scapularis nymphs at day 3 . Control samples consisted of skin from non-infested mice matching the location where ticks had bitten the infested mice. Biopsy punches of 2-mm were taken, and skin was trimmed to the proximity of the tick mouthparts. Skin samples were placed in 10\% Neutral Buffered Formalin (v/v) for 2-3 weeks before parafilm embedding. Tissue was vertically cut, and sections were hematoxylin and eosin (H/ E) stained. Pictures were taken with a Leica DFC495 microscope (Leica). The thickness of the epidermis was measured using ImageJ.

Chemokine and cytokines. I. scapularis nymphs were microinjected with vamp33 si or vamp33 sc RNAs. Microinjected ticks were placed on C57BL/6J (WT) mice and allowed to feed for 3 days before the skin biopsy. The bite site was marked with a permanent marker and ticks were removed with forceps. Skin biopsies were taken from the bite site using a 3-mm Integra Miltex disposable biopsy punch (Integra). The weight of the punch biopsies was measured using a Pioneer ${ }^{\text {to }}$ analytical balance (OHAUS). Biopsies were placed in dry ice and into $-80{ }^{\circ} \mathrm{C}$ for storage. Biopsies were homogenized in protein extraction buffer ${ }^{95}$, containing 0.5\% BSA (Sigma), 0.1\% IGEPAL ${ }^{\circ}$ CA-630 (Sigma), and $1 \%$ Halt $^{\text {"x" }}$ protease inhibitor (Thermo Scientific), and normalized by weight $(500 \mu \mathrm{l} / \mathrm{mg}$ of skin). Homogenized lysates were stored at $-80^{\circ} \mathrm{C}$ until used.

The relative concentration of the chemokines CXCL10, CXCL1, CXCL2, CCL2, CCL3, CCL4, and CCL20 were measured using the U-PLEX Chemokine Combo Mouse (Meso Scale Diagnostics) following the manufacturer's instructions. The concentration of Th1/Th2 (Interferon (IFN)- $\gamma$, Interleukin (IL)-10, IL-12p70, IL13, IL-1 $\beta$, IL-2, IL-4, IL-5 and Tumor Necrosis Factor (TNF)- $\alpha$ ) and Th17 (IFN- $\gamma$, IL-17A, IL-17C, IL-17C, IL-17E/IL-25, IL-17F, IL-21, IL-22, and IL-6) cytokines were analyzed using the U-PLEX TH1/TH2 Combo Mouse and U-PLEX TH17 Combo 2 Mouse, respectively. Samples were measured and concentrations were analyzed with the MSD discovery workbench - methodical mind version 20132019 (Meso Scale Diagnostics).

\section{Skin immune cell populations}

Cell populations affected during tick feeding. I. scapularis nymphs fed on C57BL/6J mice. At the 3rd day of feeding, mice were euthanized with $\mathrm{CO}_{2}$ and the site where ticks were feeding was shaved. A 10-mm skin punch biopsy was taken while ticks were still attached. Skin samples from control mice were taken from matching locations. Single cell suspensions were prepared from each skin sample. Briefly, skin samples were cut into small pieces with sterile surgical scissors and placed into $14 \mathrm{ml}$ FALCON ${ }^{\oplus}$ polypropylene round-bottom tubes containing $3 \mathrm{ml}$ digestion buffer consisting of 90\% RPMI-1640 (Quality Biological), 10\% Liberase ${ }^{\mathrm{mex}} \mathrm{TL}$ Research Grade (Roche), and 0.1\% DNAse I (Millipore-Sigma). Digestions were carried out for $1 \mathrm{~h}$ and $5 \mathrm{~min}$ at $37^{\circ} \mathrm{C}$ on constant shaking at $70 \mathrm{rpm}$. Single cell suspensions were obtained by passing the digested tissues through a $40-\mu \mathrm{m}$ cell strainer (Corning), homogenizing the tissue with a plunger and flushing cells with $20 \mathrm{ml}$ RPMI-1640. Cells were centrifuged at $568 \times g$ for $5 \mathrm{~min}$ at $4{ }^{\circ} \mathrm{C}$, resuspended in $1 \mathrm{ml}$ FACS buffer (PBS containing 1\% BSA). In total, $200 \mu \mathrm{l}$ of the suspension were placed into a 96-well U-bottom plate and surface-stained with antibody panels.

Granulocytes (neutrophils, macrophages, monocytes, eosinophils, and basophils) were labeled with APC/Vio770 anti-CD11c (Miltenyi Biotec 130-107461; $3 \mathrm{ng} / \mu \mathrm{l}$ ), VioBlue anti-Ly-6G (Miltenyi Biotec 130-107-461; $3 \mathrm{ng} / \mu \mathrm{l}$ ), FITC anti-Ly-6C (Miltenyi Biotec discontinued; $3 \mathrm{ng} / \mu \mathrm{l}$ ), PE anti-Siglec-f (Miltenyi Biotec 130-102-274; $3 \mathrm{ng} / \mathrm{\mu l}$ ), APC anti-CD11b (Miltenyi Biotec 130-113-793; $3 \mathrm{ng}$ / $\mu \mathrm{l})$, and PE/Vio770 anti-F4/80 (Miltenyi Biotec 130-118-459; $3 \mathrm{ng} / \mu \mathrm{l}$ ). Mast cells were labeled with APC/Vio770 anti-CD45 (Miltenyi Biotec discontinued; $3 \mathrm{ng} / \mu \mathrm{l}$ ),

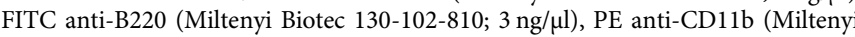
Biotec 130-113-235; $3 \mathrm{ng} / \mathrm{\mu l}$ ), APC anti-CD117 (Miltenyi Biotec 130-102-796; $3 \mathrm{ng} /$ $\mu \mathrm{l}$ ), PE/Vio700 anti-CD3ع (Miltenyi Biotec 130-102-359; $3 \mathrm{ng} / \mu \mathrm{l}$ ), and eFluor 450 anti-FceR1 (eBioscience 48589882; $2 \mathrm{ng} / \mu \mathrm{l})$. Lymphocytes ( $\mathrm{T}$ and B cells) were labeled with APC/Vio700 anti-CD8a (Miltenyi Biotec 130-102-305; $3 \mathrm{ng} / \mu \mathrm{l}$ ),

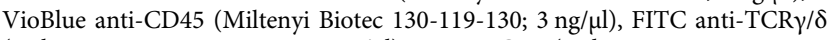
(Miltenyi Biotec 130-104-015; $3 \mathrm{ng} / \mathrm{\mu l}$ ), PE anti-CD4 (Miltenyi Biotec 130-102-619; $3 \mathrm{ng} / \mu \mathrm{l}$ ), APC anti-B220 (Miltenyi Biotec 130-102-259; $3 \mathrm{ng} / \mu \mathrm{l}$ ), and PE/Vio770 CD3 (Miltenyi Biotec 130-116-530; $3 \mathrm{ng} / \mu \mathrm{l}$ ). Live and dead cells were discriminated using propidium iodide solution (Miltenyi Biotec). Cells were incubated with an antibody panel for $10 \mathrm{~min}$ at $4{ }^{\circ} \mathrm{C}$ and washed with $1 \% \mathrm{BSA}$ in PBS with $2 \mathrm{mM}$ EDTA. Fluorescently labeled populations were measured with a MACSQuant flow cytometer (Miltenyi Biotec) and analysis was performed using the FlowJo software v 10.6.1 (Treestar).

Cell types were defined by a flow cytometry gating strategy, as indicated in Supplementary Fig. 12. Myeloid cells were gated on the $\mathrm{CD} 45^{+} \mathrm{CD} 11 \mathrm{~b}^{+}$population from live cells, and neutrophils and monocytes were identified as Ly6 $\mathrm{C}^{\mathrm{l}} \mathrm{Ly} 6 \mathrm{G}^{\mathrm{hi}}$ and $\mathrm{Ly} 6 \mathrm{C}^{\text {hi }} \mathrm{Ly} 6 \mathrm{G}^{\text {lo }}$ cells, respectively. Eosinophils were identified as $\mathrm{CD} 11 \mathrm{~b}^{+}$Siglec$\mathrm{F}^{+}$from the $\mathrm{CD} 45^{+}$population of live cells. Basophils were identified as CD11b ${ }^{+} \mathrm{FceR} 1{ }^{+}$cells from the $\mathrm{CD}_{4}{ }^{+}$population of live cells. Macrophages were identified as $\mathrm{CD} 11 \mathrm{~b}^{+} \mathrm{F} 4 / 80^{\text {int }}$ cells from the $\mathrm{CD} 45^{+}$population of live cells. DCs were identified as $\mathrm{CD} 11 \mathrm{~b}^{+} \mathrm{CD} 11 \mathrm{c}^{+}$cells from the $\mathrm{CD} 45^{+}$population of live cells. Mast cells were first gated on the $\mathrm{B} 220^{-} \mathrm{CD}^{-}$population from $\mathrm{CD}_{4} 5^{+}$cells followed by identification as $\mathrm{FceR} 1^{+} \mathrm{CD} 117^{+}$cells. T cells were identified in live cells that were first gated on $\mathrm{CD}_{4} 5^{+} . \gamma \delta \mathrm{T}$ cells, $\mathrm{CD}^{+}$, and $\mathrm{CD} 8^{+} \mathrm{T}$ cells were identified as $\mathrm{CD}^{+} \mathrm{TCR} \delta^{+}, \mathrm{CD}^{+}{ }^{+} \mathrm{CD} 4^{+}$, and $\mathrm{CD}^{+}{ }^{+} \mathrm{CD} 8^{+}$, respectively. B cells were gated on the $\mathrm{B} 220^{+}$population from $\mathrm{CD} 45^{+}$cells.

DETC populations in the murine skin were labeled with APC anti-CD45 (BioLegend 103111; 1:100), FITC anti-CD3 (BioLegend 100203; 1:100), BV60 antiVү5 (BD 743241; 1:50), monoclonal antibody 17D1 ${ }^{96}$ (kindly provided by Dr. Adrian Hayday, King's College London, and Dr. Robert Tigelaar, Yale University), and PE mouse anti-rat IgM (BD 553888; 1:100). Live and dead cells were discriminated using Zombie Violet Fixable Live Dead stain (BioLegend). Cells were washed with FACS buffer (1\% BSA in PBS with $2 \mathrm{mM}$ EDTA and $0.05 \% \mathrm{NaN} 3$ ). Cells were then blocked with anti-FcR (CD16-CD32) (BioLegend 156603; 1:500), and subsequently stained with the antibody panel for $15 \mathrm{~min}$ at $4{ }^{\circ} \mathrm{C}$ and washed with FACS buffer. Anti-rat IgM was added to the cells, incubated for $15 \mathrm{~min}$ at $4{ }^{\circ} \mathrm{C}$, and washed twice with FACS buffer. Finally, cells were resuspended in $4 \%$ paraformaldehyde, measured with an LSRII flow cytometer (BD) and analysis was performed using the FlowJo software v 10.6.1.

Cells populations affected by EVs. Exosome biogenesis was reduced in I. scapularis nymphs with vamp33 si. Control I. scapularis nymphs were microinjected with vamp33 sc. Nymphs fed for 3 days and skin samples were taken as described above.

$\gamma \delta \mathbf{T}$ cell depletion. C57BL/6J mice were injected intraperitoneally (i.p.) with 500 $\mu \mathrm{g}$ of InVivoMAb anti-mouse TCR $\gamma / \delta$ clone UC7-13D5 (BioCell BE0070) or InVivoMAb polyclonal Armenian hamster IgG (BioCell BE0091; control) on the day (day -1) and on the morning (day 0) prior to tick placement. Ticks were microinjected with vamp33 si or vamp33 sc. Ticks fed on $\gamma \delta$ T cell-depleted and isotype control mice for 3 days. Mice were euthanized on the third day. Tick weights were measured. Depletion was confirmed through FACS measurement of $\gamma \delta$ T cells in the skin and spleens. Skin were labeled using VioBlue anti-CD45 (Miltenyi Biotec 130-119-130; $3 \mathrm{ng} / \mu \mathrm{l}$ ), FITC anti-TCR $\gamma / \delta$ (Miltenyi Biotec 130104-015; $3 \mathrm{ng} / \mu \mathrm{l}$ ), PE/Vio770 CD3 (Miltenyi Biotec 130-116-530; $3 \mathrm{ng} / \mu \mathrm{l}$ ), and PE anti-TCR $\beta$ Chain (BD 553172; $2 \mathrm{ng} / \mu \mathrm{l}$ ). Live and dead cells were discriminated using propidium iodide solution (Miltenyi Biotec). $\mathrm{T}$ cell populations were measured with a MACSQuant flow cytometer and analysis was performed using FlowJo software v 10.6.1. 
Genetic ablation of $\boldsymbol{\alpha} \boldsymbol{\beta}$ and $\boldsymbol{\gamma} \boldsymbol{\delta}$ T Cells. Ticks were microinjected with $v a m p 33$ si or vamp33sc and placed on C57BL/6J (WT), $c c r 2^{-1-}, c c r 6^{-/-}, t c r \delta^{-/-}, t c r \beta^{-/-}$, FVB/N Jax, and FVB/N Tac mice. Ticks fed for 3 days and their weight was measured.

FTY720 treatment in mice. C57BL/6J (WT) mice were injected intraperitoneally (i.p.) with FTY720 (Sigma-Aldrich), $1 \mathrm{mg} / \mathrm{kg}$ in $100 \mu \mathrm{L}$ sterile water on days -1 and on the morning of day 0 prior to tick placement.

Ticks were microinjected with vamp33 si or vamp33 sc. Ticks fed on FTY720injected and PBS-injected mice for 3 days. Mice were euthanized on the third day. Tick weights were measured. In all, $10 \mathrm{~mm}$ skin punch biopsies and draining lymph nodes were obtained from euthanized mice. FTY720 treatment was confirmed through FACS measurement of lymphocytes in the skin and draining lymph nodes. Skin and lymph node samples were labeled using APC-Cy7 antiCD45 (Miltenyi Biotec 130-110-662; 3 ng/ $\mu$ ), VioBlue anti-CD4 (Miltenyi Biotec 130-118-568; $3 \mathrm{ng} / \mu \mathrm{l}$ ), PerCP-Vio700 anti-TCR $\gamma / \delta$ (Miltenyi Biotec 130-117-665; $3 \mathrm{ng} / \mu \mathrm{l}$ ), and PECy7 CD3 (Miltenyi Biotec 130-116-530; $3 \mathrm{ng} / \mu \mathrm{l}$ ). Live and dead cells were discriminated using propidium iodide solution (Miltenyi Biotec). Cell populations were measured with a MACSQuant flow cytometer and analysis was performed using FlowJo software v 10.6.1.

\section{Intracellular bacterium infection}

A. phagocytophilum model. Female C57BL/6 mice were shaved in three different spots on the back. Cell-free A. phagocytophilum $\left(1 \times 10^{7}\right.$ bacteria/injection) resuspended in $50 \mu \mathrm{l}$ of PBS were intradermally (i.d.) injected into these spots in the presence or absence of $4 \times 10^{7} \mathrm{I}$. scapularis nymphal salivary EVs. Infections progressed for $48 \mathrm{~h}$ and animals were euthanized using $\mathrm{CO}_{2}$. Blood samples were taken by heart puncture and divided into two specimens: half of the blood in a serum collection tube and the other half in EDTA Microvette ${ }^{\circledast} 200 \mu$ lubes (Sarstedt Ag). Skin biopsies were taken from each injection site, and spleens and livers were dissected. Skin and spleen samples were placed at $-80^{\circ} \mathrm{C}$. DNA was extracted from skin samples, using the DNeasy Blood \& Tissue Kit (QIAGEN) according to a modified version of a previously described protocol ${ }^{97}$. Briefly, the samples were grinded in liquid nitrogen $\left(\mathrm{LN}_{2}\right)$, using a mortar and pestle. Ground tissues were resuspended in $180 \mu \mathrm{l}$ ATL Buffer and $20 \mu \mathrm{l}$ of proteinase $\mathrm{K}$. Tissues were incubated at $56^{\circ} \mathrm{C}$ overnight. DNA purification was followed using the manufacturer's specification. DNA was eluted in $100 \mu \mathrm{l}$ of elution buffer. DNA concentration was measured with a NanoDrop Spectrophotometer ND-1000 (Thermo Fisher Scientific)

Bacterial numbers at the skin site, blood, and other organs were measured by amplifying the single copy $16 s$ gene ${ }^{98}$. Gene expression was normalized by the mouse actin gene listed in Supplemental Data 6 . Genes were amplified under the following conditions: a denaturation cycle of $10 \mathrm{mins}$ at $95^{\circ} \mathrm{C}$, followed by 40 cycles of denaturalization for $15 \mathrm{~s}$ at $95^{\circ} \mathrm{C}$, amplification at two different annealing temperatures (A. phagocytophilum $16 \mathrm{~s}: 48^{\circ} \mathrm{C}$ and mouse actin: $55^{\circ} \mathrm{C}$ ) for $1 \mathrm{~min}$. Bacterial quantification was performed with the Bio-Rad CFX96 Real-Time System through the CFX Maestro Software 1.1. The presence of a single peak was confirmed with the melting curve. Cytokines were measured as described above. Serum samples were centrifuged at $16,100 \times g$ for $5 \mathrm{~min}$ after $30 \mathrm{~min}$ incubation at room temperature. Serum samples were stored at $-80^{\circ} \mathrm{C}$ until use. Th1/Th2 cytokines were measured with the U-PLEX TH1/TH2 Combo Mouse, using a 1:2 dilution and following the manufacturer's recommendations.

F. tularensis model. F. tularensis live vaccine strain (LVS) was grown from glycerol stocks on Mueller Hinton Broth (MHB) plates (2.1\% Mueller Hinton Broth (w/v; Difco), $0.5 \%$ sodium chloride (w/v; Fisher Scientific), 1\% Tryptone (w/v; BD), 1.6\% agar (w/v; BD), $0.1 \%$ glucose (w/v; Millipore-Sigma), $0.025 \%$ ferric pyrophosphate (w/v; Millipore-Sigma), 2\% IsoVitalex (v/v; BD), and 10\% sheep whole blood (v/v; Lampire) for 2 days at $37^{\circ} \mathrm{C}$ with $5 \% \mathrm{CO}_{2}$. Bacteria were scrapped off and resuspended in MHB broth (2.1\% Mueller Hinton Broth (w/v; Difco), calcium chloride $0.014 \%$ (w/v; Millipore-Sigma), magnesium chloride $1 \mathrm{mM}$ (v/v; American Bioanalytical), $0.1 \%$ glucose (w/v; Millipore-Sigma), $0.025 \%$ ferric pyrophosphate (w/v; Millipore-Sigma), and $2 \%$ IsoVitalex (v/v; BD) for stocks at $1.48 \times 10^{11} \mathrm{CFU} /$ $\mathrm{ml}$ that were frozen at $-80^{\circ} \mathrm{C}$. Female mice were injected with bacteria at various concentrations to determine the correct lethal intradermal dose. The stock of bacteria was diluted to give $7.5 \times 10^{6}, 7.5 \times 10^{7}$, and $7.5 \times 10^{8} \mathrm{CFU}$ of bacteria in $50 \mu \mathrm{l}$ of endotoxin-free PBS. The inoculum was confirmed by serial dilution plating onto $\mathrm{MHB}$ plates and allowed to grow for 2 days at $37^{\circ} \mathrm{C}$ with $5 \% \mathrm{CO}_{2}$. Infected mice were monitored twice a day until they showed signs of distress at which point they were monitored every hour until all animals died. Weight loss of each animal was also measured daily. To establish the effect of EVs derived from the adult female D. andersoni salivary glands during the infection of $F$. tularensis, 10 female mice per group were i.d. injected with $8.4 \times 10^{7} \mathrm{CFU}$ of bacteria in the presence or absence of $1 \times 10^{8} \mathrm{EVs}$, and weight loss and survival were monitored, as described above.

To determine how tick salivary vesicles affected bacterial numbers and the inflammatory response to $F$. tularensis, mice were i.d. injected with $6.7-6.8 \times 10^{7}$ CFU of bacteria in the presence or absence of EVs $\left(1 \times 10^{8}\right.$ /injection $)$ derived from adult female $D$. andersoni salivary glands. Three independent experiments were performed and two out of three F. tularensis mouse infection challenges showed similar results. Infection progressed for 5 days under daily monitoring. At day 5 , animals were euthanized, and the weight of the animals was taken. Organs (spleens, livers, and lungs) were dissected and weighed. Blood samples were taken in Microvette $^{\circledR} 200 \mu$ l tubes for serum (Sarstedt Ag). Spleens were weighed with a Pioneer $^{\text {rm }}$ analytical balance (OHAUS) and corrected by the weight of the mice to establish the degree of splenomegaly. Sections of organs were used to quantify the number of bacteria by homogenizing the organs in $500 \mu \mathrm{l}$ of PBS inside $2.0 \mathrm{ml}$ BeadBug $^{\text {Tm }}$ tubes, prefilled with $1.5 \mathrm{~mm}$ Zirconium beads, triple-pure, high impact (Benchmark Scientific), with a benchmark BeadBug Microtube Homogenizer Model D1030(E) (Benchmark Scientific). Pieces of organs were homogenized at $400 \times 10$ speed for $90 \mathrm{~s}$. Homogenates were serially diluted and $10 \mu \mathrm{l}$ from the $1 \times$ $10^{-1}$ to $1 \times 10^{-5}$ dilutions were plated onto MHB plates, which were incubated for 2 days at $37^{\circ} \mathrm{C}$ with $5 \% \mathrm{CO}_{2}$ before colonies were counted. CFUs of bacteria were normalized by the weight of the organs. Th1/Th2 cytokines in serum were analyzed using the U-PLEX Th1/Th2 Combo Mouse, using a 1:10 dilution for Francisellachallenged mice (with or without EVs) and 1:2 for the control mice (PBS alone or PBS and EVs).

Tick acquisition and transmission of $\boldsymbol{F}$. tularensis. One day prior to tick placement, $\mathrm{C} 3 \mathrm{H} / \mathrm{HeN}$ mice were anesthetized with a ketamine-xylazine sedative, an area $\sim 2.5 \mathrm{~cm}$ in diameter between the shoulder blades was shaved with surgical clippers, and plastic chambers (top portion of $15-\mathrm{mL}$ conical tubes) were adhered to shaved skin using Kamar adhesive. Mice were individually housed to prevent chamber removal by cage mates. The next day (day -5), mice were anesthetized, nymphal $D$. variabilis ticks were placed in each chamber, chambers were closed with a fine-mesh polyester fabric, and fabric was secured to each chamber using a rubber band. Double-sided tape was adhered to the inside upper rim of each cage bottom and cages were placed onto tack mats to prevent loss of any escaped ticks.

Three days after tick placement (day -2), mice were anesthetized, and intravenously infected with LVS. Bacterial inoculum was serially diluted and plated in quadruplet onto sMHA to confirm CFUs. Approximately $48 \mathrm{~h}$ after infection (day 0), mice were anesthetized, replete ticks were collected, and blood was harvested from infected mice by cardiac puncture for serial dilution in PBS and plating. To determine bacterial numbers in ticks at various time points after repletion (e.g., day 0 , week 2 , week 4 , week 6 , etc.), ticks were first surface-sterilized by placing into $30 \% \mathrm{H}_{2} \mathrm{O}_{2}$ for five seconds, $70 \%$ ethanol for $5 \mathrm{~s}$, washed with molecular grade water (Corning) for 5 seconds, then homogenized in RNAse-free disposable pellet pestle tubes (Fisher) containing $200 \mu \mathrm{L}$ of sterile PBS. Tick homogenates were serially diluted in PBS and plated onto MHA containing 100 $\mathrm{mg} / \mathrm{L}$ cycloheximide, $80,000 \mathrm{U} / \mathrm{L}$ polymyxin $\mathrm{B}$, and $2.5 \mathrm{mg} / \mathrm{L}$ amphotericin $\mathrm{B}$. Following $72 \mathrm{~h}$ of incubation, the number of colonies per plate were counted and $\mathrm{CFU} / \mathrm{ml}$ (mouse blood) or CFU/tick were calculated.

Infection studies were performed essentially as described above, with the following modifications: LVS-infected adult ticks (14 weeks after their nymphal blood meal) were individually placed into chambers and allowed to feed to repletion on naïve mice. Repleted adult ticks were collected 8 days after tick placement and were either immediately homogenized for bacterial enumeration (day 8) or homogenized for bacterial enumeration when associated mice were moribund (days 14-18). To quantitate bacterial burdens in mouse blood and tissues during infection studies, mouse blood/tissues were either collected on day 8 (tick repletion) or when mice were moribund and humanely euthanized (days 14-18). Mice were anesthetized, blood was collected by cardiac puncture, mice were cervically dislocated, skin from the tick attachment site was harvested using a $8 \mathrm{~mm}$ biopsy punch (Accuderm), and lungs, livers, and spleens were aseptically harvested and transferred to sterile Whirlpack bags. Samples were homogenized, $25 \mu \mathrm{l}$ of PBS/mg of tissue was added to each tissue, serially diluted, and dilutions were plated onto media.

Ethics statement. Blood collections were performed on healthy volunteers who provided informed consent. The protocol was approved by the Institutional Review Board (IRB\# HP-00040025) of the University of Maryland School of Medicine and comply with the $21 \mathrm{CFR}$ part 50. I. ricinus feeding experiments were performed in accordance with the Animal Protection Law of the Czech Republic (\$17, Act No. 246/1992 Sb) and with the approval of the Akademie Věd České Republiky (approval no. 161/2010). All mouse experiments were carried out under the guidelines approved by the Institutional Biosafety (IBC\#00002247) and Animal Care and Use committees (IACUC\#0216015 and \#0119012) at the University of Maryland School of Medicine and (IACUC\#108672 and IBC\#108665) at the University of Toledo College of Medicine and Life Sciences according to the National Institutes of Health (NIH) guidelines (Office of Laboratory Animal Welfare (OLAW) \#A3200-01, A323-01, and A3270-1). Calf experiments were done in accordance with the guidelines approved by the IACUC at the University of Idaho (IACUC\# 2017-59).

Statistical analysis. Statistical significance of each experiment was assessed with the unpaired one or two-tailed Student's $t$ test. One-way or Two-way ANOVA post-hoc Sidak test for multiple comparisons and Two-way ANOVA followed by Fisher's least significance difference statistical tests were also used whenever appropriate. Survival curves were analyzed with the Kaplan-Meier followed by the 
Log-rank (Mantel-Cox) test. We used GraphPad PRISM ${ }^{\circledast}$ (GraphPad Software version 9.1.0) for all statistical analyses. Outliers were detected by a Graphpad Quickcals program (https://www.graphpad.com/quickcalcs/Grubbsl.cfm).

Reporting summary. Further information on research design is available in the Nature Research Reporting Summary linked to this article.

\section{Data availability}

The mass spectrometry proteomics data have been deposited to the ProteomeXchange Consortium via the PRIDE ${ }^{99}$ partner repository with the dataset identifier PXD018779 under the project name "Label free proteomics profiling of nanovesicle isolated from cultured salivary glands isolated from partially fed adult female Ixodes scapularis" Project https://doi.org/10.6019/PXD018779. All other data are available upon reasonable request. Raw data from all experiments are available as Source Data file. Source data are provided with this paper.

Received: 14 October 2019; Accepted: 24 May 2021; Published online: 17 June 2021

\section{References}

1. WHO. Vector-borne Diseases (2017).

2. Nuttall P. A. Tick saliva and its role in pathogen transmission. Wiener Klinische Wochenschrift https://doi.org/10.1007/s00508-019-1500-y (2019).

3. Simo, L., Kazimirova, M., Richardson, J. \& Bonnet, S. I. The essential role of tick salivary glands and saliva in tick feeding and pathogen transmission. Front. Cell. Infect. Microbiol. 7, 281 (2017).

4. Wikel, S. Ticks and tick-borne pathogens at the cutaneous interface: host defenses, tick countermeasures, and a suitable environment for pathogen establishment. Front. Microbiol. 4, 337 (2013).

5. Titus, R. G. \& Ribeiro, J. M. Salivary gland lysates from the sand fly Lutzomyia longipalpis enhance Leishmania infectivity. Science 239, 1306-1308 (1988).

6. Limesand, K. H., Higgs, S., Pearson, L. D. \& Beaty, B. J. Potentiation of vesicular stomatitis New Jersey virus infection in mice by mosquito saliva. Parasite Immunol. 22, 461-467 (2000).

7. Cox, J., Mota, J., Sukupolvi-Petty, S., Diamond, M. S. \& Rico-Hesse, R. Mosquito bite delivery of dengue virus enhances immunogenicity and pathogenesis in humanized mice. J. Virol. 86, 7637-7649 (2012).

8. Fialova, A., Cimburek, Z., Iezzi, G. \& Kopecky, J. Ixodes ricinus tick saliva modulates tick-borne encephalitis virus infection of dendritic cells. Microbes Infect. 12, 580-585 (2010).

9. Wang, X. et al. The tick protein Sialostatin L2 binds to Annexin A2 and inhibits NLRC4-mediated inflammasome activation. Infect. Immun. 84, 1796-1805 (2016).

10. Marchal, C. et al. Antialarmin effect of tick saliva during the transmission of Lyme disease. Infect. Immun. 79, 774-785 (2011)

11. Ramamoorthi, N. et al. The Lyme disease agent exploits a tick protein to infect the mammalian host. Nature 436, 573-577 (2005).

12. Titus, R. G., Bishop, J. V. \& Mejia, J. S. The immunomodulatory factors of arthropod saliva and the potential for these factors to serve as vaccine targets to prevent pathogen transmission. Parasite Immunol. 28, 131-141 (2006).

13. Pingen, $M$. et al. Host inflammatory response to mosquito bites enhances the severity of arbovirus infection. Immunity 44, 1455-1469 (2016).

14. Peters, N. C. et al. In vivo imaging reveals an essential role for neutrophils in leishmaniasis transmitted by sand flies. Science 321, 970-974 (2008).

15. Kalluri, R. \& LeBleu, V. S. The biology, function, and biomedical applications of exosomes. Science 367, eaau6977 (2020).

16. Pegtel D. M., Gould S. J. Exosomes. Ann. Rev. Biochem. 88, 487-514 (2019).

17. Mathieu, M., Martin-Jaular, L., Lavieu, G. \& Thery, C. Specificities of secretion and uptake of exosomes and other extracellular vesicles for cell-to-cell communication. Nat. Cell Biol. 21, 9-17 (2019).

18. Zhou, W., Woodson, M., Sherman, M. B., Neelakanta, G. \& Sultana, H. Exosomes mediate Zika virus transmission through SMPD3 neutral Sphingomyelinase in cortical neurons. Emerg. Microbes Infect. 8, 307-326 (2019).

19. Vora, A. et al. Arthropod EVs mediate dengue virus transmission through interaction with a tetraspanin domain containing glycoprotein Tsp29Fb. Proc. Natl Acad. Sci. USA 115, E6604-E6613 (2018).

20. Regmi, P., Khanal, S., Neelakanta, G. \& Sultana, H. Tick-borne flavivirus inhibits Sphingomyelinase (IsSMase), a venomous spider ortholog to increase sphingomyelin lipid levels for its survival in Ixodes scapularis Ticks. Front. Cell. Infect. Microbiol. 10, 244 (2020).

21. Gold, A. S. et al. Dengue virus infection of Aedes aegypti alters extracellular vesicle protein cargo to enhance virus transmission. Int. J. Mol. Sci. 21, 6609 (2020).
22. Nawaz, M. et al. Proteomic analysis of exosome-like vesicles isolated from saliva of the tick Haemaphysalis longicornis. Front. Cell. Infect. Microbiol. 10, 542319 (2020).

23. Nawaz, M. et al. miRNA profile of extracellular vesicles isolated from saliva of Haemaphysalis longicornis tick. Acta Tropica 212, 105718 (2020).

24. Eisen, R. J. \& Eisen, L. The blacklegged tick, Ixodes scapularis: an increasing public health concern. Trends Parasitol. 34, 295-309 (2018).

25. Kendall, B. L. et al. Characterization of flavivirus infection in salivary gland cultures from male Ixodes scapularis ticks. PLoS Negl. Trop. Dis. 14, e0008683 (2020).

26. Grabowski, J. M. et al. Dissecting flavivirus biology in salivary gland cultures from fed and unfed Ixodes scapularis (Black-Legged Tick). mBio 10, e02628-18 (2019)

27. Grabowski, J. M. et al. Flavivirus infection of Ixodes scapularis (Black-Legged Tick) Ex Vivo organotypic cultures and applications for disease control. mBio 8, e01255-17 (2017)

28. Nielsen, M. M., Witherden, D. A. \& Havran, W. L. $\gamma \delta$ T cells in homeostasis and host defence of epithelial barrier tissues. Nat. Rev. Immunol. 17, 733-745 (2017).

29. Havran, W. L. \& Jameson, J. M. Epidermal T cells and wound healing. J. Immunol. 184, 5423-5428 (2010).

30. Hayday, A. C. $\gamma \delta$ T cell update: adaptate orchestrators of immune surveillance. J. Immunol. 203, 311-320 (2019).

31. Havran, W. L. Specialized antitumor functions for skin $\gamma \delta$ T cells. J. Immunol. 200, 3029-3030 (2018).

32. Macleod, A. S. \& Havran, W. L. Functions of skin-resident $\gamma \delta$ T cells. Cell. Mol. Life Sci. 68, 2399-2408 (2011).

33. Ribot, J. C., Lopes, N. \& Silva-Santos, B. $\gamma \delta$ T cells in tissue physiology and surveillance. Nat. Rev. Immunol. 21, 221-232 (2020).

34. Jameson, J. et al. A role for skin $\gamma \delta \mathrm{T}$ cells in wound repair. Science 296, 747-749 (2002)

35. Hayday, A. C. \& Vantourout, P. The innate biologies of adaptive antigen receptors. Annu. Rev. Immunol. 38, 487-510 (2020).

36. Gulia-Nuss, M. et al. Genomic insights into the Ixodes scapularis tick vector of Lyme disease. Nat. Commun. 7, 10507 (2016)

37. Jaworski, D. C., Cheng, C., Nair, A. D. \& Ganta, R. R. Amblyomma americanum ticks infected with in vitro cultured wild-type and mutants of Ehrlichia chaffeensis are competent to produce infection in naive deer and dogs. Ticks Tick. Borne Dis. 8, 60-64 (2017).

38. Reif, K. E., Ujczo, J. K., Alperin, D. C. \& Noh, S. M. Francisella tularensis novicida infection competence differs in cell lines derived from United States populations of Dermacentor andersoni and Ixodes scapularis. Sci. Rep. 8, 12685 (2018).

39. de la Fuente, J. Controlling ticks and tick-borne diseases looking forward. Ticks Tick. Borne Dis. 9, 1354-1357 (2018).

40. Zhang, H. et al. Identification of distinct nanoparticles and subsets of extracellular vesicles by asymmetric flow field-flow fractionation. Nat. Cell Biol. 20, 332-343 (2018).

41. Zhou, W. et al. Discovery of exosomes from tick saliva and salivary glands reveals therapeutic roles for CXCL12 and IL- 8 in wound healing at the tick-human skin interface. Front. Cell Dev. Biol. 8, 554 (2020).

42. Suzuki, Y. J. Oxidant-mediated protein amino acid conversion. Antioxidants 8, 50 (2019).

43. Sprong, H. et al. ANTIDotE: anti-tick vaccines to prevent tick-borne diseases in Europe. Parasit. Vectors 7, 77 (2014).

44. Hoshino, A. et al. Tumour exosome integrins determine organotropic metastasis. Nature 527, 329-335 (2015).

45. Wallace, P. K. et al. Tracking antigen-driven responses by flow cytometry: monitoring proliferation by dye dilution. Cytometry A 73, 1019-1034 (2008).

46. Glatz, M., Means, T., Haas, J., Steere, A. C. \& Mullegger, R. R. Characterization of the early local immune response to Ixodes ricinus tick bites in human skin. Exp. Dermatol. 26, 263-269 (2017).

47. McKenzie, D. R. et al. IL-17-producing $\gamma \delta$ T cells switch migratory patterns between resting and activated states. Nat. Commun. 8, 15632 (2017).

48. Chiba, K. et al. FTY720, a novel immunosuppressant, induces sequestration of circulating mature lymphocytes by acceleration of lymphocyte homing in rats. I. FTY720 selectively decreases the number of circulating mature lymphocytes by acceleration of lymphocyte homing. J. Immunol. 160, 5037-5044 (1998).

49. Bernard, Q., Grillon, A., Lenormand, C., Ehret-Sabatier, L. \& Boulanger, N. Skin interface, a key player for Borrelia multiplication and persistence in Lyme borreliosis. Trends Parasitol. 36, 304-314 (2020).

50. Gray, E. E., Suzuki, K. \& Cyster, J. G. Identification of a motile IL-17producing $\gamma \delta \mathrm{T}$ cell population in the dermis. J. Immunol. 186, 6091-6095 (2011).

51. Heilig, J. S. \& Tonegawa, S. Diversity of murine gamma genes and expression in fetal and adult T lymphocytes. Nature 322, 836-840 (1986). 
52. Boyden, L. M. et al. Skint1, the prototype of a newly identified immunoglobulin superfamily gene cluster, positively selects epidermal gammadelta T cells. Nat. Genet. 40, 656-662 (2008).

53. Baardman, J. et al. A defective pentose phosphate pathway reduces inflammatory macrophage responses during hypercholesterolemia. Cell Rep. 25, 2044-2052 (2018). e2045.

54. Chen, G. et al. Anaplasma phagocytophilum dihydrolipoamide dehydrogenase 1 affects host-derived immunopathology during microbial colonization. Infect. Immun. 80, 3194-3205 (2012).

55. Cannizzo, E. S. et al. Age-related oxidative stress compromises endosomal proteostasis. Cell Rep. 2, 136-149 (2012).

56. Conlan, J. W., Chen, W., Bosio, C. M., Cowley, S. C. \& Elkins, K. L. Infection of mice with Francisella as an immunological model. Curr. Protoc. Immunol. Chapter 19, Unit 1914 (2011).

57. Coburn, J. et al. Reproducible and quantitative model of infection of Dermacentor variabilis with the live vaccine strain of Francisella tularensis. Appl. Environ. Microbiol. 81, 386-395 (2015).

58. Tully, B. G. \& Huntley, J. F. A. Francisella tularensis chitinase contributes to bacterial persistence and replication in two major U.S. tick vectors. Pathogens 9, 037 (2020).

59. Goethert, H. K. \& Telford, S. R.3rd Quantum of infection of Francisella tularensis tularensis in host-seeking Dermacentor variabilis. Ticks Tick-Borne Diseases 1, 66-68 (2010).

60. Feldman, K. A. et al. An outbreak of primary pneumonic tularemia on Martha's Vineyard. N. Engl. J. Med. 345, 1601-1606 (2001).

61. Belkaid, Y. \& Tamoutounour, S. The influence of skin microorganisms on cutaneous immunity. Nat. Rev. Immunol. 16, 353-366 (2016).

62. Telford, S. R. 3rd \& Goethert, H. K. Ecology of Francisella tularensis. Annu. Rev. Entomol. 65, 351-372 (2020).

63. Parker R. R., Spencer R. R., Francis E., United states Public Health Service. Tularaemia infection in ticks of the species Dermacentor andersoni Stiles in the Bitterroot Valley Mont. (Government Printing Office, 1924).

64. Green, R. G. The occurrence of Bacterium tularense in the eastern wood tick, Dermacentor variabilis. Am. J. Epidemiol. 14, 600-613 (1931).

65. Gong, H. et al. Blocking the secretion of saliva by silencing the HlYkt6 gene in the tick Haemaphysalis longicornis. Insect Biochem. Mol. Biol. 39, 372-381 (2009).

66. Karim, S. et al. Identification of SNARE and cell trafficking regulatory proteins in the salivary glands of the lone star tick, Amblyomma americanum (L.) Insect Biochem. Mol. Biol. 32, 1711-1721 (2002).

67. Karim, S., Miller, N. J., Valenzuela, J., Sauer, J. R. \& Mather, T. N. RNAimediated gene silencing to assess the role of synaptobrevin and cystatin in tick blood feeding. Biochem. Biophys. Res. Commun. 334, 1336-1342 (2005).

68. Karim, S., Ramakrishnan, V. G., Tucker, J. S., Essenberg, R. C. \& Sauer, J. R. Amblyomma americanum salivary glands: double-stranded RNA-mediated gene silencing of synaptobrevin homologue and inhibition of $\mathrm{PGE}_{2}$ stimulated protein secretion. Insect Biochem. Mol. Biol. 34, 407-413 (2004).

69. Lai, C. P. et al. Visualization and tracking of tumour extracellular vesicle delivery and RNA translation using multiplexed reporters. Nat. Commun. 6, 7029 (2015).

70. Verweij, F. J. et al. Live tracking of inter-organ communication by endogenous exosomes In Vivo. Dev. Cell 48, 573-589 e574 (2019).

71. Daniel E. S. \& R. M. Roe. Biology of Ticks, 2nd edn (Oxford University Press, 2014).

72. Kim, T. K. et al. Ixodes scapularis tick saliva proteins sequentially secreted every $24 \mathrm{~h}$ during blood feeding. PLoS Negl. Trop. Dis. 10, e0004323 (2016).

73. Tirloni, L. et al. Tick-host range adaptation: changes in protein profiles in unfed adult Ixodes scapularis and Amblyomma americanum saliva stimulated to feed on different hosts. Front. Cell. Infect. Microbiol. 7, 517 (2017).

74. Zamanian, M. et al. Release of small RNA-containing exosome-like vesicles from the human filarial parasite Brugia malayi. PLoS Negl. Trop. Dis. 9, e0004069 (2015).

75. Sisquella, X. et al. Malaria parasite DNA-harbouring vesicles activate cytosolic immune sensors. Nat. Commun. 8, 1985 (2017).

76. Zhou, W. et al. Exosomes serve as novel modes of tick-borne flavivirus transmission from arthropod to human cells and facilitates dissemination of viral RNA and proteins to the vertebrate neuronal cells. PLoS Pathog. 14, e1006764 (2018).

77. Allen, J. R., Khalil, H. M. \& Wikel, S. K. Langerhans cells trap tick salivary gland antigens in tick-resistant guinea pigs. J. Immunol. 122, 563-565 (1979).

78. Lahmers, K. K. et al. Comparative gene expression by $\mathrm{WC} 1^{+} \gamma \delta$ and $\mathrm{CD} 4^{+} \alpha \beta$ $\mathrm{T}$ lymphocytes, which respond to Anaplasma marginale, demonstrates higher expression of chemokines and other myeloid cell-associated genes by $\mathrm{WCl}^{+}$ $\gamma \delta$ T cells. J. Leukoc. Biol. 80, 939-952 (2006).

79. Shi, C. et al. Reduced immune response to Borrelia burgdorferi in the absence of $\gamma \delta$ T cells. Infect. Immun. 79, 3940-3946 (2011).

80. Boppana, D. K. et al. In vivo immunomodulatory effects of ixodid ticks on ovine circulating T- and B-lymphocytes. Parasite Immunol. 26, 83-93 (2004).
81. Chodaczek, G., Papanna, V., Zal, M. A. \& Zal, T. Body-barrier surveillance by epidermal $\gamma \delta$ TCRs. Nat. Immunol. 13, 272-282 (2012).

82. Sharp, L. L., Jameson, J. M., Cauvi, G. \& Havran, W. L. Dendritic epidermal $\mathrm{T}$ cells regulate skin homeostasis through local production of insulin-like growth factor 1. Nat. Immunol. 6, 73-79 (2005).

83. Shaw, D. K. et al. Vector immunity and evolutionary ecology: the harmonious dissonance. Trends Immunol. 39, 862-873 (2018).

84. Munderloh, U. G., Liu, Y., Wang, M., Chen, C. \& Kurtti, T. J. Establishment, maintenance and description of cell lines from the tick Ixodes scapularis. J. Parasitol. 80, 533-543 (1994).

85. Oliva Chavez, A. S. et al. An O-methyltransferase is required for infection of tick cells by Anaplasma phagocytophilum. PLoS Pathog. 11, e1005248 (2015).

86. Labandeira-Rey, M. \& Skare, J. T. Decreased infectivity in Borrelia burgdorferi strain B31 is associated with loss of linear plasmid 25 or 28-1. Infect. Immun. 69, 446-455 (2001).

87. Ganta, R. R. et al. Differential clearance and immune responses to tick cellderived versus macrophage culture-derived Ehrlichia chaffeensis in mice. Infect. Immun. 75, 135-145 (2007).

88. Ren, G., Champion, M. M. \& Huntley, J. F. Identification of disulfide bond isomerase substrates reveals bacterial virulence factors. Mol. Microbiol. 94, 926-944 (2014).

89. Hackenberg, M., Langenberger, D., Schwarz, A., Erhart, J. \& Kotsyfakis, M. In silico target network analysis of de novo-discovered, tick saliva-specific microRNAs reveals important combinatorial effects in their interference with vertebrate host physiology. RNA 23, 1259-1269 (2017).

90. Michael, A. et al. Exosomes from human saliva as a source of microRNA biomarkers. Oral Dis. 16, 34-38 (2010).

91. Zlotogorski-Hurvitz, A. et al. Human saliva-derived exosomes: comparing methods of isolation. J. Histochem. Cytochem. 63, 181-189 (2015).

92. Nesvizhskii, A. I., Keller, A., Kolker, E. \& Aebersold, R. A statistical model for identifying proteins by tandem mass spectrometry. Anal. Chem. 75, 4646-4658 (2003)

93. Noel, G. et al. A primary human macrophage-enteroid co-culture model to investigate mucosal gut physiology and host-pathogen interactions. Sci. Rep. 7, 45270 (2017)

94. van der Vlist, E. J., Nolte-'t Hoen, E. N., Stoorvogel, W., Arkesteijn, G. J. \& Wauben, M. H. Fluorescent labeling of nano-sized vesicles released by cells and subsequent quantitative and qualitative analysis by high-resolution flow cytometry. Nat. Protoc. 7, 1311-1326 (2012).

95. Heinze, D. M., Wikel, S. K., Thangamani, S. \& Alarcon-Chaidez, F. J. Transcriptional profiling of the murine cutaneous response during initial and subsequent infestations with Ixodes scapularis nymphs. Parasit. Vectors 5, 26 (2012).

96. Mallick-Wood, C. A. et al. Conservation of $\mathrm{T}$ cell receptor conformation in epidermal $\gamma \delta$ cells with disrupted primary $\mathrm{V} \gamma$ gene usage. Science $\mathbf{2 7 9}$, 1729-1733 (1998).

97. Grasperge, B. J., Morgan, T. W., Paddock, C. D., Peterson, K. E. \& Macaluso, K. R. Feeding by Amblyomma maculatum (Acari: Ixodidae) enhances Rickettsia parkeri (Rickettsiales: Rickettsiaceae) infection in the skin. J. Med. Entomol. 51, 855-863 (2014).

98. Niu, H., Xiong, Q., Yamamoto, A., Hayashi-Nishino, M. \& Rikihisa, Y. Autophagosomes induced by a bacterial Beclin 1 binding protein facilitate obligatory intracellular infection. Proc. Natl Acad. Sci. USA 109, 20800-20807 (2012).

99. Perez-Riverol, Y. et al. The PRIDE database and related tools and resources in 2019: improving support for quantification data. Nucleic Acids Res. 47, D442-D450 (2019).

\section{Acknowledgements}

We thank Jon Skare (Texas A\&M University Health Science Center) for providing the $B$ burgdorferi B31 strain, clone MSK5; Dr. Adrian Hayday (King's College London) and Dr. Robert Tigelaar (Yale University) for the monoclonal antibody 17D1; Ulrike G. Munderloh (University of Minnesota) for supplying ISE6, DAE100, and AAE2 tick cells; Regina Harley (University of Maryland School of Medicine) for flow cytometry assistance; Anthony Kim, Aniket Wadajikar (University of Maryland School of Medicine) and Tek Lamichhane (University of Maryland College Park) for technical support with the EV characterization; Ru-Ching Hsia and Joseph Mauban (University of Maryland School of Medicine) for aiding in the microscopy analysis; J. Stephen Dumler (University of Maryland School of Medicine) for providing the E. chaffeensis Arkansas strain; Jonathan Oliver (University of Minnesota) for making available I. scapularis ticks; Gaelle Noel (University of Maryland School of Medicine) for technical assistance with the isolation of human peripheral blood mononuclear cells and differentiation to macrophages; Katharina Richard and Stefanie Vogel (University of Maryland School of Medicine) for providing the F. tularensis LVS strain; and Cristiana Cairo (University of Maryland School of Medicine) for insightful advice related to $\gamma \delta$ T cells. This work was supported by grants from the National Institutes of Health (NIH) and the National Science Foundation (NSF) to J.H.F.P. (R01AI134696, R01AI116523 and R01 AI049424), J.H.F.P. and U.P. (P01AI138949), U.P. (R01AI116620), E.E.M.C. (F31AI138440), A.J.O. 
(F31AI152215), E.M.B. (R01AI123129) and S.M.J. (R01HL141611 and 1750542). This article was prepared while Amanda D. Buskirk, Ph.D. was employed at the University of Maryland School of Medicine and Center for Vaccine Development and Global Health. The content is solely the responsibility of the authors and does not necessarily represent the official views of the NIH, NSF, FDA, the Department of Health and Human Services or the United States government.

\section{Author contributions}

A.S.O.C. performed the research with contributions from X.W., L.M., N.K.A., H.L.H., D.K.S., B.G.T., E.E.M.C., S.L.F., L.R.B., P.S., A.D.B., K.M., L.L., C.C.C., A.J.O., K.L.M., B.E.H., D.E.S., and M.K. Reagents and advice were provided by C.B.M., J.G.V., M.F.P., M.B.S., U.P., S.M.J., J.F.H., L.M., G.A.S., E.M.B., M.L.L., and L.S. The project was developed by A.S.O.C. and supervised by J.H.F.P with input from L.S., M.K., E.M.B., and L.S.M. The paper was written by A.S.O.C. and J.H.F.P. with help from the other authors.

\section{Competing interests}

L.S.M. is a full-time employee of Janssen Pharmaceuticals and holds Johnson \& Johnson stock. L.S.M. performed all work at his prior affiliation at Johns Hopkins University School of Medicine and he has received prior grant support from AstraZeneca, Pfizer, Boehringer Ingelheim, Regeneron Pharmaceuticals, and Moderna Therapeutics. L.S.M. was also a paid consultant for Armirall, AstraZeneca, Moderna Therapeutics and Janssen Research and Development. L.S.M. was on the scientific advisory board of Integrated Biotherapeutics and is a shareholder of Noveome Biotherapeutics. All of these aforementioned companies are developing therapeutics against infections and/or inflammatory conditions. The remaining authors declare not competing interest.

\section{Additional information}

Supplementary information The online version contains supplementary material available at https://doi.org/10.1038/s41467-021-23900-8.

Correspondence and requests for materials should be addressed to J.H.F.P.

Peer review information Nature Communications thanks the anonymous reviewer(s) for their contribution to the peer review of this work. Peer reviewer reports are available.

Reprints and permission information is available at http://www.nature.com/reprints

Publisher's note Springer Nature remains neutral with regard to jurisdictional claims in published maps and institutional affiliations.

\begin{abstract}
(c) (i) Open Access This article is licensed under a Creative Commons Attribution 4.0 International License, which permits use, sharing, adaptation, distribution and reproduction in any medium or format, as long as you give appropriate credit to the original author(s) and the source, provide a link to the Creative Commons license, and indicate if changes were made. The images or other third party material in this article are included in the article's Creative Commons license, unless indicated otherwise in a credit line to the material. If material is not included in the article's Creative Commons license and your intended use is not permitted by statutory regulation or exceeds the permitted use, you will need to obtain permission directly from the copyright holder. To view a copy of this license, visit http://creativecommons.org/ licenses/by/4.0/.
\end{abstract}

(C) The Author(s) 2021 